\title{
Proline metabolism and transport in retinal health and disease
}

\author{
Jianhai Du ${ }^{1,2,4} \oplus \cdot$ Siyan Zhu ${ }^{1,2} \cdot$ Rayne R. Lim ${ }^{3} \cdot$ Jennifer R. Chao ${ }^{3}$ \\ Received: 19 February 2021 / Accepted: 10 April 2021 / Published online: 19 April 2021 \\ (c) The Author(s), under exclusive licence to Springer-Verlag GmbH Austria, part of Springer Nature 2021
}

\begin{abstract}
The retina is one of the most energy-demanding tissues in the human body. Photoreceptors in the outer retina rely on nutrient support from the neighboring retinal pigment epithelium (RPE), a monolayer of epithelial cells that separate the retina and choroidal blood supply. RPE dysfunction or cell death can result in photoreceptor degeneration, leading to blindness in retinal degenerative diseases including some inherited retinal degenerations and age-related macular degeneration (AMD). In addition to having ready access to rich nutrients from blood, the RPE is also supplied with lactate from adjacent photoreceptors. Moreover, RPE can phagocytose lipid-rich outer segments for degradation and recycling on a daily basis. Recent studies show RPE cells prefer proline as a major metabolic substrate, and they are highly enriched for the proline transporter, SLC6A20. In contrast, dysfunctional or poorly differentiated RPE fails to utilize proline. RPE uses proline to fuel mitochondrial metabolism, synthesize amino acids, build the extracellular matrix, fight against oxidative stress, and sustain differentiation. Remarkably, the neural retina rarely imports proline directly, but it uptakes and utilizes intermediates and amino acids derived from proline catabolism in the RPE. Mutations of genes in proline metabolism are associated with retinal degenerative diseases, and proline supplementation is reported to improve RPE-initiated vision loss. This review will cover proline metabolism in RPE and highlight the importance of proline transport and utilization in maintaining retinal metabolism and health.
\end{abstract}

Keywords Proline $\cdot$ Metabolism $\cdot$ Transport $\cdot$ Retina $\cdot$ Retinal pigment epithelium $\cdot$ Retinal disease

$\begin{array}{ll}\text { Abbreviations } \\ \text { RPE } & \text { Retinal pigment epithelium } \\ \text { PRODH } & \text { Proline dehydrogenase } \\ \text { SLC } & \text { Solute carrier family } \\ \text { OAT } & \text { Ornithine aminotransferase } \\ \text { P5C } & \text { Pyrroline-5-carboxylate } \\ \text { TCA cycle } & \text { Tricarboxylic acid cycle } \\ \text { TGF- } \beta & \text { Transforming growth factor-beta } \\ \text { EMT } & \text { Epithelial-to-mesenchymal transition }\end{array}$

Handling editor: J. M Phang.

Jianhai Du

jianhai.du@hsc.wvu.edu

1 Department of Ophthalmology and Visual Sciences, West Virginia University, Morgantown, WV 26506, USA

2 Department of Biochemistry, West Virginia University, Morgantown, WV 26506, USA

3 Department of Ophthalmology, University of Washington, Seattle, WA 98109, USA

4 One Medical Center Dr, WVU Eye Institute, PO Box 9193, Morgantown, WV 26505, USA
AMD Age-related macular degeneration

PVR Proliferative vitreoretinopathy

\section{Introduction}

Vertebrate retinas are light-sensitive neuronal tissues with large metabolic demands for phototransduction, maintenance of ion gradients, and biosynthesis of daily-shed photoreceptor outer segments (Hurley et al. 2015). Due to the absence of a direct blood supply, photoreceptors must absorb nutrients, including glucose, amino acids, fatty acids, ketone bodies and vitamins through the retinal pigment epithelium (RPE) (Du et al. 2013; Hurley et al. 2015; Li et al. 2020). The RPE consists of a monolayer of polarized epithelial cells that transports metabolites between the choroidal blood supply and the outer retina. Similar to tumor cells, retinas have robust aerobic glycolysis (the Warburg effect) and produce large amounts of lactate from glucose. In turn, RPE utilizes lactate from the Warburg effect as a fuel to preserve glucose for the retina (Kanow et al. 2017). RPE phagocytizes $\sim 10 \%$ of outer segments shed from photoreceptors each day and 
processes them into fatty acids and ketone bodies as metabolic substrates for the retina (Adijanto et al. 2014; ReyesReveles et al. 2017). RPE could also recycle succinate into malate to feed the retina (Bisbach et al. 2020). This synergistic effect is crucial for photoreceptor survival, as metabolic dysfunction or degeneration of RPE can result in photoreceptor degeneration, leading to blindness in retinal degenerative diseases, including inherited retinal degenerations and age-related macular degeneration (AMD) (Ferrington et al. 2020; Lefevere et al. 2017; Zhao et al. 2011a). Likewise, separation of the neural retina from RPE in retinal detachment causes rapid photoreceptor degeneration (Lo et al. 2011). Of note, recent studies demonstrate that RPE prefers to use proline as a metabolic substrate, and dietary proline protects retinas from degeneration induced by the oxidative damage in the RPE (Chao et al. 2017; Yam et al. 2019). Mutations of genes involved in proline metabolism have previously been shown to cause inherited retinal degeneration (O'Donnell et al. 1978; Wolthuis et al. 2014). Furthermore, the proline transporter, SLC6A20, is highly enriched in the RPE and is associated with macular thickness (Bennis et al. 2015; Gao et al. 2019; Strunnikova et al. 2010). This review discusses proline transport and metabolism in RPE and how proline can affect retinal metabolism, retinal health, and retinal degenerative diseases.

\section{Proline catabolism, synthesis and transport in RPE}

\section{The metabolic fate of proline}

The RPE is capable of using proline as a major metabolic substrate. Typical RPE culture medium contains $0.447 \mathrm{mM}$ proline, which is almost completely consumed within $24 \mathrm{~h}$ in primary human RPE culture (Chao et al. 2017; Yam et al. 2019). Infusion of ${ }^{13} \mathrm{C}$ proline in vivo also shows that RPE actively consumes this substrate (Yam et al. 2019). Why does RPE need so much free proline? The fate of proline utilization includes the synthesis into proline-rich proteins and catabolism into ornithine and glutamate for the urea cycle and mitochondrial tricarboxylic acid (TCA) cycle (Fig. 1).

Proline makes up to $25 \%$ of collagen, the most abundant protein in the human body (Phang et al. 2010). Collagen is a major component of the extracellular matrix (ECM), which is very dynamic in its turnover to interact with cytokines and growth factors in response to cellular environmental changes. RPE cells attach to a collagen-rich, five-layered ECM structure called Bruch's membrane (BrM), a molecular sieve for small molecule exchange between RPE and choroid blood circulation (Murali et al. 2020). RPE is critical for the composition, stability and thickness of BrM in healthy and diseased conditions (Campochiaro et al. 1986). ${ }^{14} \mathrm{C}$-proline tracing showed that cultured RPE synthesizes and secretes collagen in a time-dependent manner, peaking between 60 and 108 days (Li et al. 1984). Proline analogs such as cis-hydroxyproline and azetidine carboxylic acid can incorporate into collagen polypeptides, destabilizing the collagen structure, inhibiting collagen synthesis and accelerating collagen degradation (Tan et al. 1983; Uitto et al. 1984). Cis-hydroxyproline inhibits RPE proliferation and collagen synthesis, while simultaneous addition of proline to the culture blocks these inhibitory effects (Yoo et al. 1997). The thickness of ECM underneath the RPE cell layer can reach $30 \mu \mathrm{M}$ after 360 days of culture (Kigasawa et al. 1998). About half of proline in collagen peptides is post-translationally modified into 4-hydroxyproline or 3-hydroxyproline by prolyl-4-hydroxylase or prolyl-3-hydroxylase (Wu et al. 2011). This hydroxylation is important for increasing the stability of the collagen triple helix structure. Aside from the 28 classic collagens, many other proteins contain collagen-like triple helix domains, including complement 1q (C1q), adiponectin, ficolins, and macrophage receptors (Ricard-Blum 2011). These proteins are critical in immune recognition and anti-inflammation, both of which are involved in the pathogenesis of AMD (Cao et al. 2015; Nita et al. 2014a; Tan et al. 2020).

Proline is catabolized through flavin-dependent proline dehydrogenase (PRODH) in the mitochondrial matrix into pyrroline-5-carboxylate (P5C) (Fig. 1). PRODH can donate electrons directly to ubiquinone through $\mathrm{FADH}_{2}$. $\mathrm{P} 5 \mathrm{C}$ is a key intermediate in proline metabolism, as it connects with other amino acids and also serves as a precursor for proline synthesis. P5C produces glutamate through a NAD-dependent P5C dehydrogenase (P5CDH), encoded by ALDH4Al gene in the mitochondria. Glutamate, an important neurotransmitter in the retinal neurons, is also a precursor for glutamine, gamma-aminobutyric acid (GABA) and mitochondrial TCA cycle intermediates ( $\mathrm{Li}$ et al. 2020). Glutamate can convert into $\alpha \mathrm{KG}$ to enter the TCA cycle through either glutamate dehydrogenase or transaminases such as aspartate transaminase (AST), alanine transaminase (ALT), and phosphoserine aminotransferase (PSAT). RPE relies on aminotransferases rather than glutamate dehydrogenase for this process (Xu et al. 2020). Proline stimulates the production of glutamate, aspartate, alanine, serine, $\alpha \mathrm{KG}$, and other TCA cycle intermediates in human RPE culture, whereas the inhibition of PRODH substantially decreases these metabolites (Chao et al. 2017). Similar to cancer cells, RPE cells can use reductive carboxylation that produces mitochondrial citrate directly from $\alpha K G$ through NADP-dependent isocitrate dehydrogenase 2 (IDH2). This reductive carboxylation allows for the synthesis of citrate without acetyl-CoA and the export of NADPH into the cytosol to confer resistance to oxidative damage (Du et al. 2016). Tracing with ${ }^{13} \mathrm{C}$ proline 


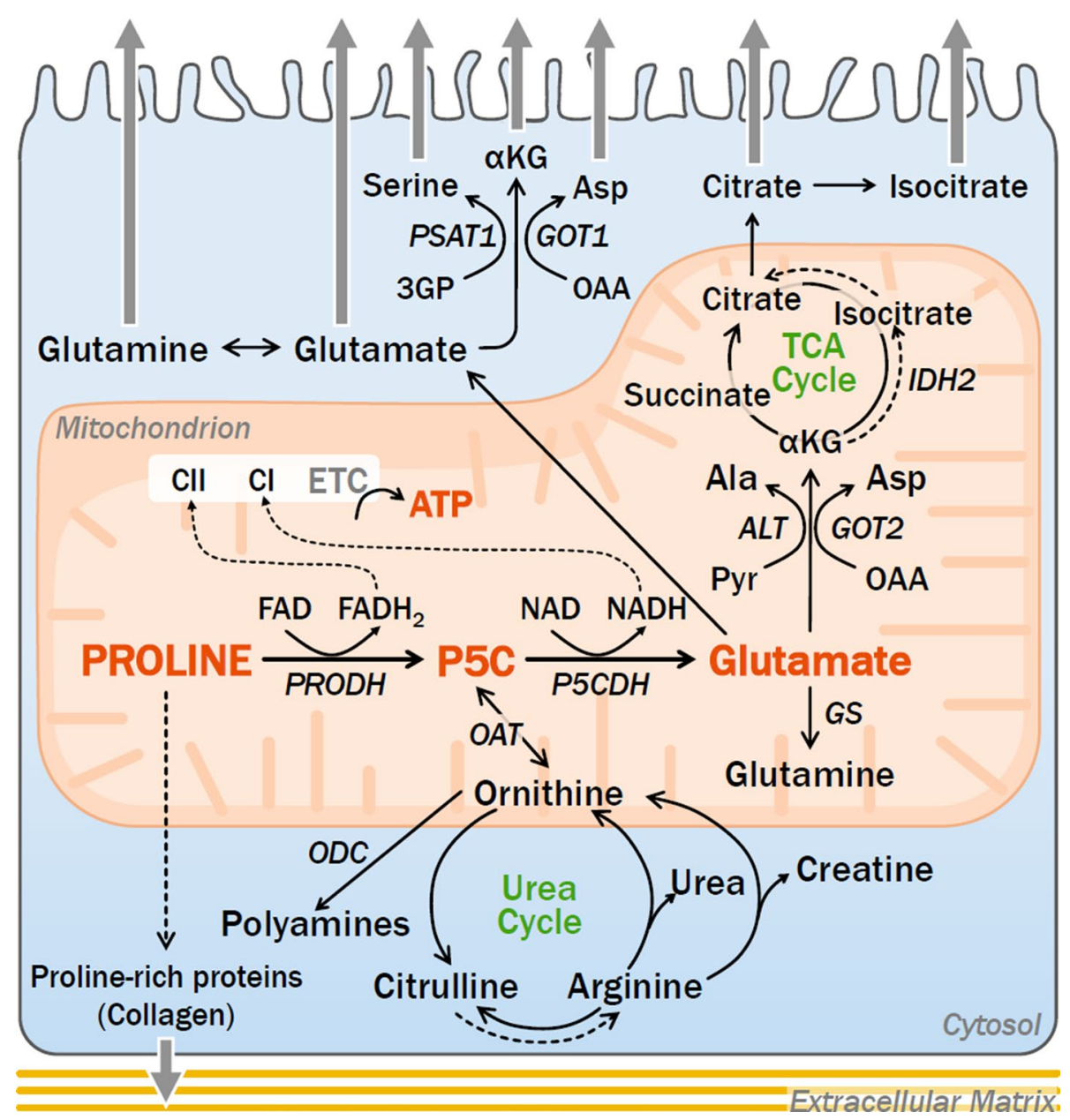

Fig. 1 The metabolic fate of proline. Proline is catabolized into P5C, a key intermediate which serves as a precursor for glutamate, glutamine and ornithine. $\mathrm{FADH}_{2}$ and $\mathrm{NADH}$ from the catabolism fuel the electron transport chain to generate ATP. Glutamate can be transaminated into $\alpha \mathrm{KG}$, producing alanine, aspartate and serine. RPE is highly efficient in reductive carboxylation, generating mitochondrial citrate directly from $\alpha \mathrm{KG}$ through IDH2. Substrates including glutamine, glutamate, serine, $\alpha \mathrm{KG}$, aspartate, citrate and isocitrate are exported to the apical photoreceptors. P5C is reversibly converted into ornithine depending on the availability of precursors. Ornithine enters the urea cycle to produce arginine, citrulline, and

in RPE shows that proline can efficiently be catabolized through this reductive carboxylation pathway (Chao et al. 2017).

P5C can also reversibly convert into ornithine through ornithine aminotransferase (OAT), depending on the availability of P5C or ornithine. Ornithine is a critical intermediate in the urea cycle and is closely involved in the metabolism of arginine, citrulline, creatine and polyamines (Wu et al. 2005) (Fig. 1). In neonates, OAT is an important source for arginine. OAT whole-body knockout mice die within 2 days of birth with symptoms of ornithine deficiency but survive with arginine administration (Wang et al. 1995). Human creatine. Ornithine is also a precursor for polyamines. Additionally, proline is incorporated into proteins, especially proline-rich proteins such as collagen to form the RPE extracellular matrix. 3PG 3-phosphoglycerate, $\alpha K G$ alpha-ketoglutarate, Ala alanine, $A L T$ alanine transaminase, Asp aspartate, AST aspartate transaminase (GOT1 \& GOT2 isozymes), GS glutamine synthetase, $I D H 2$ isocitrate dehydrogenase 2, OAA oxaloacetate, $O A T$ ornithine aminotransferase, $O D C$ ornithine decarboxylase, $P 5 C$ pyrroline-5-carboxylate, $P 5 C D H$ P5C dehydrogenase, $P R O D H$ proline dehydrogenase, $P S A T$ phosphoserine aminotransferase, $P y r$ pyruvate

neonates with OAT deficiency have low concentrations of ornithine and citrulline but high concentrations of proline in their plasma (de Sain-van der Velden et al. 2012). In cultured human fetal RPE, ${ }^{13} \mathrm{C}$ proline labels about half of the pool of ornithine within one hour (Chao et al. 2017), confirming that OAT is active and that ornithine turns over rapidly in the RPE.

\section{Sources of free proline}

In addition to dietary intake, the major sources of proline in mammalian tissues are from de novo synthesis and 
degradation of proline-enriched proteins such as collagen. Glutamate, glutamine, ornithine and arginine are precursors for proline synthesis, but the pathways can be cell- and species-specific (Fig. 2). P5C is the common intermediate in proline synthesis. Glutamate and glutamine can produce $\mathrm{P} 5 \mathrm{C}$ through P5C synthase (P5CS), encoded by the ALDH18A1 gene. P5CS is an ATP- and NADPH-dependent mitochondrial enzyme. Patients with mutations of ALDH18Al have hypoprolinemia and retinal degeneration (Baumgartner et al. 2000, 2005; Wolthuis et al. 2014). Fibroblasts from these patients are deficient in their ability to convert glutamate into proline for protein synthesis, demonstrating that proline synthesis from glutamate is critical for normal proline metabolism. Ornithine and arginine can convert into P5C through the reverse reaction of OAT. The direction towards proline synthesis is dominant in adults, which is the opposite of neonates (de Sain-van der Velden et al. 2012; Wang et al. 1995). The abnormalities of OAT mutations in patients are limited to gyrate atrophy in the eye (Mitsubuchi et al. 2008), suggesting that there might be a special need for proline metabolism in the RPE and retina.

Proline synthesis from P5C needs NAD(P)H-dependent $\mathrm{P} 5 \mathrm{C}$ reductase (PYCR). PYCR has three known isoforms using both NADH and NADPH. PYCR1 and 2 are located in the mitochondria and prefer $\mathrm{NADH}$ as the co-factor, while PYCR3 is located in the cytosol and prefers NADPH (Fig. 2). The expression of PYCR isoforms is cell-specific, and different isoforms may contribute differently to proline synthesis. In Lu1205 cells, knockdown of PYCR1 and PYCR2 reduce the ratio of proline to glutamate, while knockdown of PYCR3 decreases the ratio of proline to ornithine (De Ingeniis et al. 2012). It is postulated that PYCR3 and PRODH can work together to shuttle proline between mitochondria and cytosol, also called the proline cycle. This cycle can transfer electrons from NADPH into the mitochondria and stimulate flux of the pentose phosphate pathway (PPP) (Phang et al. 2010). Mutations of PYCRs have similar clinical features to $A L D H 18 A 1$ but without visual defects (Wolthuis et al. 2014). Although, the knockout of PYCR1 in zebrafish shows disrupted RPE and retinal degeneration (Liang et al. 2019).

Proline incorporated proteins are another important source of free proline. Proline-rich collagen can serve as a reservoir to store proline. During stress or nutrient-deprivation, collagen degrades into proline to fuel energy metabolism (Olivares et al. 2017). Collagen can be cleaved into peptides by proteases such as matrix metalloproteinases (MMPs), which are inhibited by specific endogenous tissue inhibitors of MMPs (TIMPs). MMPs and TIMPs are critical regulators of ECM turnover and remodeling. Glucose

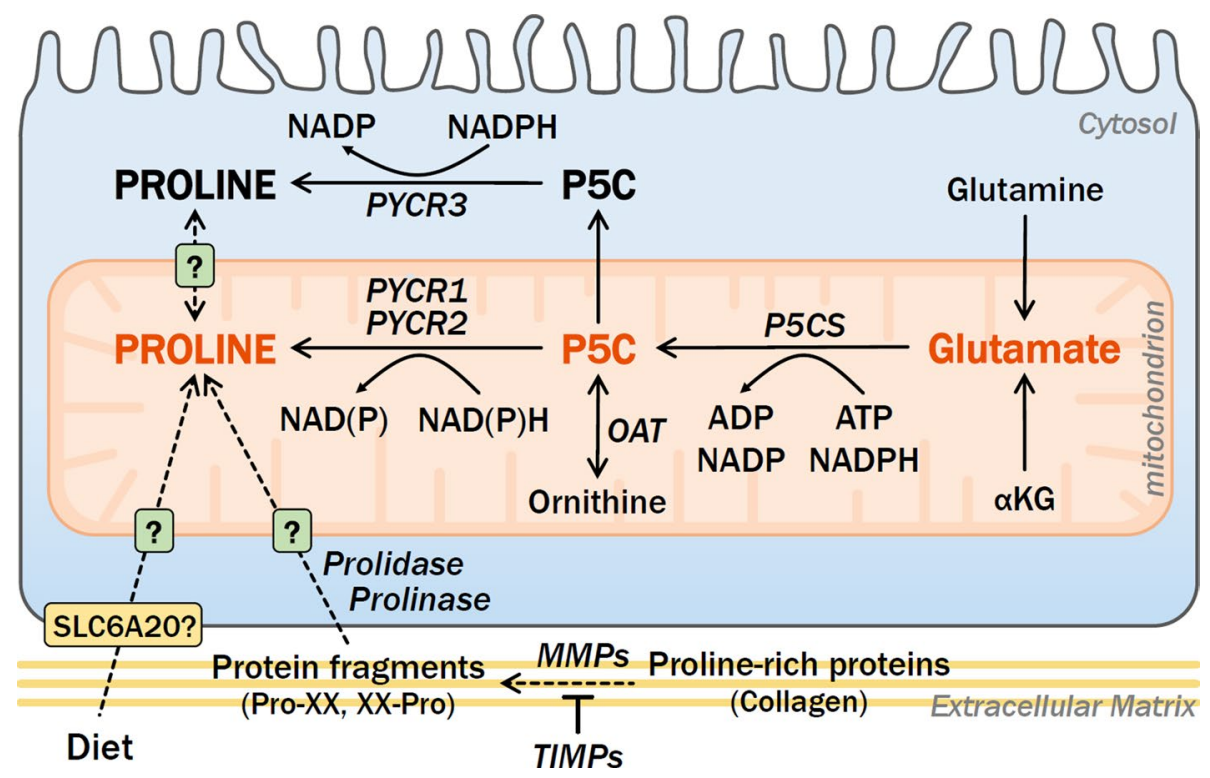

Fig. 2 Sources of proline in RPE. Dietary proline is taken up by RPE cells likely through SLC6A20 transporter. Collagen and other proline-rich proteins are degraded via MMPs, and proline-containing fragments are further degraded into free proline by prolidase and prolinase enzymes. TIMPs are endogenous inhibitors of MMPs, whose mutation results in excess degradation of ECM. Proline is also generated via de novo synthesis from glutamate and ornithine substrates. Glutamate is converted into P5C intermediate through P5CS, which is then reduced to proline by PYCRs. Ornithine and arginine can also convert into proline via reverse reaction of OAT. Biosynthesis of proline is energetically expensive, requiring $2 \mathrm{NADPH}$ and 1 ATP from glutamate or glutamine pathway, and $1 \mathrm{NAD}(\mathrm{P}) \mathrm{H}$ from arginine or ornithine pathway. The genetic identity of transporters responsible for proline transport between cytosol and mitochondria is still unknown. $\alpha K G$ alpha-ketoglutarate, $M M P$ matrix metalloproteinases, $O A T$ ornithine aminotransferase, P5C pyrroline-5-carboxylate, P5CS P5C synthase, PYCR1,2,3 P5C reductase (isoforms 1,2,3), TIMP tissue inhibitors of MMP 
stress, hypoxia and inflammation can activate MMPs to degrade collagen (Pandhare et al. 2009; Phang et al. 2010). Mutations of many ECM genes including MMPs and TIMPs are associated with retinal degeneration (Anand-Apte et al. 2019; Garcia-Onrubia et al. 2020); however, how the abnormal ECM turnover impairs proline supply and metabolism in RPE remains unknown.

Cells can take up MMP-hydrolyzed collagen fragments through the urokinase receptor associated protein (uPARAP/ Endo 180), and further degrade them into tripeptides, dipeptides and free amino acids by cathepsins and peptidases (Curino et al. 2005; Phang et al. 2010). The unique pyrrolidine ring in proline induces conformational constraints on the peptide bond to protect the iminopeptides from hydrolysis by most peptidases (Cunningham and O'Connor 1997). Prolidase and prolinase are the only known enzymes that are capable of hydrolyzing proline-containing dipeptides, also called iminodipeptides, into free proline. Prolidase such as peptidase D (PEPD) specifically hydrolyzes C-terminal proline, while prolinase such as dipeptidyl peptidase IV (DPP4) and its family, specifically cleaves off $\mathrm{N}$-terminal proline
(Misiura and Miltyk 2020; Waumans et al. 2015). In addition to collagen, many bioactive peptides contain proline to protect them from unexpected degradation. Prolidase and prolinase can degrade proline in these peptides to modulate the immune response, cell growth and neural development (Dunaevsky et al. 2020; Misiura and Miltyk 2020). Mutations of PEPD gene can cause prolidase deficiency, a rare autosomal recessive disorder with severe skin lesions, immunodeficiency and mental retardation (Kitchener and Grunden 2012). Some PEPD deficiency patients also have ocular symptoms including amblyopia, keratitis, optic atrophy, and chorioretinal atrophy (Ogata et al. 1981).

\section{Proline transport and transporters}

Proline requires specific transporters for its cellular import and export to maintain proline homeostasis. Twelve transporters are capable of transporting proline (Table 1). SLC6A20 is the only proline transporter that is highly enriched in the RPE/choroid (Takanaga et al. 2005b). Multiple independent findings demonstrate that SLC6A2O or the

Table 1 List of proline transporters in humans

\begin{tabular}{|c|c|c|c|c|c|c|}
\hline Gene & Synonym & Substrates* & Tissue specificity & Localization & Ions** & References \\
\hline SLC6A7 & PROT & Pro & Brain & Membrane & $\mathrm{Na}^{+}, \mathrm{Cl}^{-}$ & Shafqat et al. (1995) \\
\hline SLC6A15 & B0AT2 & Leu, Val, Ile, Met, Pro & Brain & Nucleus, vesicles & $\mathrm{Na}^{+}$ & Takanaga et al. (2005a) \\
\hline SLC6A17 & NTT4 & $\begin{array}{l}\text { Leu, Met, Pro, Cys, Ala, } \\
\text { Gln, Ser, His, Gly }\end{array}$ & Brain & Vesicles & $\mathrm{Na}^{+}, \mathrm{Cl}^{-}$ & $\begin{array}{l}\text { Hagglund et al. (2013); } \\
\text { Zaia and Reimer (2009) }\end{array}$ \\
\hline SLC6A19 & B0AT1 & $\begin{array}{l}\text { Leu, Met, Ile, Val, Asn, } \\
\text { Phe, Ala, Ser, Thr, Gly, } \\
\text { Pro }\end{array}$ & Intestine & Membrane & $\mathrm{Na}^{+}$ & Broer (2006) \\
\hline $\begin{array}{l}\text { SLC6A20 } \\
\text { Slc6a20a (mouse) }\end{array}$ & SIT1 & Pro, betaine, 4-OH-Pro & $\begin{array}{l}\text { RPE/choroid, } \\
\text { intestine, } \\
\text { kidney }\end{array}$ & Membrane & $\mathrm{Na}^{+}, \mathrm{Cl}^{-}$ & $\begin{array}{l}\text { Broer et al. (2009); Kow- } \\
\text { alczuk et al. (2005) }\end{array}$ \\
\hline SLC36A1 & PAT1 & $\begin{array}{l}\text { Ala, Gly, GABA, taurine, } \\
\text { Pro, 4-OH-Pro }\end{array}$ & Brain, intestine & $\begin{array}{l}\text { Membrane, lysosome, } \\
\text { nucleus }\end{array}$ & $\mathrm{H}^{+}$ & $\begin{array}{l}\text { Jensen et al. (2014); } \\
\text { Schroder et al. (2007) }\end{array}$ \\
\hline SLC36A2 & PAT2 & $\begin{array}{l}\text { Ala, Gly, Pro, 4-OH-Pro, } \\
\text { scarosine }\end{array}$ & Kidney, muscle & Membrane & $\mathrm{H}^{+}$ & Kennedy et al. (2005) \\
\hline SLC36A4 & PAT4 & Trp, Pro & Ubiquitous & $\begin{array}{l}\text { Membrane, cytosol, } \\
\text { Golgi }\end{array}$ & Unknown & Pillai and Meredith (2011) \\
\hline SLC38A1 & SNAT1 & $\begin{array}{l}\text { Ala, Ser, Gln, Asn, His, } \\
\text { Cys, Met, Gly, Thr, Pro, } \\
\text { Tyr,Val }\end{array}$ & Ubiquitous & Membrane & $\mathrm{Na}^{+}$ & Albers et al. (2001) \\
\hline SLC38A2 & SNAT2 & $\begin{array}{l}\text { Ala, Met, Asn, Gln, Ser, } \\
\text { Pro, Gly, Thr, Leu, Phe }\end{array}$ & Ubiquitous & Membrane, vesicles & $\mathrm{Na}^{+}$ & Hatanaka et al. (2000) \\
\hline SLC38A4 & SNAT4 & $\begin{array}{l}\text { His, Arg, Ala, Asn, Lys, } \\
\text { Gly, Gln, Ser, Pro, Leu, } \\
\text { Phe }\end{array}$ & Liver & Membrane & $\mathrm{Na}^{+}$ & Hatanaka et al. (2001) \\
\hline SLC1A4 & ASCT1 & $\begin{array}{l}\text { Cys, Ala, Ser, Thr, Pro, } \\
\text { 4-OH-Pro }\end{array}$ & Brain & Membrane & $\mathrm{Na}^{+}$ & Pinilla-Tenas et al. (2003) \\
\hline
\end{tabular}

4-OH-Pro 4-hydroxyproline, Ala alanine, Arg arginine, Asn asparagine, Cys cysteine, GABA gamma-aminobutyric, Gln glutamine, Gly glycine, His histidine, Ile isoleucine, Leu leucine, Lys lysine, Met methionine acid, Phe phenylalanine, Pro proline, Ser serine, Thr threonine, Trp tryptophan, Tyr tyrosine, Val valine

*Substrates are listed in the order of affinity from high to low. **Ions co-transported with the substrates 
mouse homologue Slc6a20a is a highly conserved gene. By comparing the expression of mature human RPE cells with 53 human tissues, Liu et al. found that SLC6A20 is an RPEspecific gene (Liu et al. 2019). By comparing the expression of genes from native and cultured RPE with 78 different tissues, Sheldon Miller and colleagues selected 154 "RPE signature genes" including SLC6A20 that were expressed tenfold higher in the RPE than any other tissues (Strunnikova et al. 2010). Similarly, Liao et al. profiled global gene expression of stem-cell-derived RPE cells, native and cultured human fetal RPE cells. They identified a set of 87 RPE signature genes in which SLC6A2O is one of them (Liao et al. 2010). Meanwhile, Arthur Bergen and colleagues profiled native human RPE and native C57 mouse RPE, and found SLC6A2O or Slc6a20a as one of the 22 signature genes shared by both human and mouse RPE (Bennis et al. 2015). Interestingly, proline consumption increases during RPE differentiation (Yam et al. 2019), and SLC6A20 transcripts are substantially upregulated during RPE maturation, whereas other proline transporters are either not detected or unchanged (Radeke et al. 2015). These reports strongly suggest that SLC6A20 is responsible for mediating the robust proline consumption in differentiated RPE.

SLC6A20 is $\mathrm{Na}^{+}$and $\mathrm{Cl}^{-}$dependent. Two $\mathrm{Na}^{+}$and one $\mathrm{Cl}^{-}$molecule are co-transported together with each proline molecule (Broer et al. 2009). Human SLC6A20 is a unique gene with two transcript variants. Compared to variant 1 , variant 2 lacks an alternate in-frame exon, resulting in a shorter protein. Mouse SLC6A20 has two homologous genes, Slc6a2Oa and Slc6a2Ob, located next to each other along the gene locus. Slc6a20a has $92 \%$ homology as human SLC6A20 and is functionally active in transporting proline (Kowalczuk et al. 2005). Slc6a20b has a longer N-terminus with $81 \%$ identity to human SLC6A20 but does not transport proline or other amino acids; hence its function still remains unknown (Kowalczuk et al. 2005).

In addition to RPE, SLC6A20 is also found in epithelial cells of the intestine, kidney and lung. SLC6A20 genetic polymorphisms are associated with Hirschsprung's disease, iminoglycinuria, degenerative macular diseases and severe Covid-19 with respiratory failure (Ellinghaus et al. 2020; Gao et al. 2018; Kim et al. 2014; Lee et al. 2016; Xie et al. 2019). Hirschsprung's disease is a congenital and heterogeneous disorder characterized by missing nerves in the colon. The availability of proline may be important for neuronal cell development. Iminoglycinuria, a rare inherited disorder associated with multiple genetic mutations of glycine and proline transporters, results in poor amino acid absorption in the kidney and excess urinary excretion of proline, hydroxyproline and glycine. In humans, the macula is responsible for central, high acuity vision. Macular degenerative diseases such as AMD can result in structural changes to reduce macular thickness. A genome-wide association study (GWAS) of 68,423 participants identifies 139 loci associated with macular thickness, and SLC6A2O is one of the four most significant loci (Gao et al. 2018). Furthermore, SLC6A20 expression is downregulated in retinas from human donors with AMD (Ratnapriya et al. 2019). Interestingly, a GWAS study of severe Covid-19 patients with respiratory failure identifies SLC6A20 as one of six associated genes (Ellinghaus et al. 2020). SLC6A20 can functionally interact with angiotensin-converting enzyme 2 (ACE2), the receptor for Covid-19 spike glycoprotein in the intestine and lung (Camargo et al. 2020; Singer et al. 2012; Wang et al. 2020). The expression of ACE2 in the RPE is very low, but the overexpression of ACE2 shows protection against RPE cell death and diabetic retinopathy (Dominguez et al. 2016; Fu et al. 2017). It is unclear whether this protective mechanism is associated with SLC6A20 function. Despite many genetic association studies, the significance of SLC6A20 in physiology and disease remains largely unknown.

In addition to plasma transporters, proline also needs to be transported across the mitochondrial membrane to be oxidized by PRODH and P5CDH, located in the mitochondrial matrix. An early study of isolated rat liver mitochondria showed that proline does not travel through mitochondria by free diffusion but instead by an unidentified energy-dependent transporter (Meyer 1977). Using ${ }^{14} \mathrm{C}$ proline and spectroscopic measurements in isolated rat kidney mitochondria, Atlante et al. characterized two mitochondrial proline transporters: proline uniporter and proline/ glutamate antiporter (Atlante et al. 1994). A mitochondrial proline transporter was also characterized in tsetse fly flight muscle mitochondria, which primarily use proline for energy (Njagi et al. 1992). Although the biochemical properties of mitochondrial proline transporters have been extensively characterized, the genetic identities of these transporters a still unknown.

\section{Proline metabolism in retinal health}

\section{RPE uses proline as a metabolic fuel to nourish the neural retina}

Proline is an energy substrate in many organisms including bacteria, plants, and animals (McDonald et al. 2018). Some species such as the tsetse fly and Colorado potato beetle use proline as the primary fuel to power their flight. Interestingly, the utilization of proline in their muscles stimulates lipolysis of the fat body to synthesize more proline (Arrese and Soulages 2010). Proline can serve as an "alternative fuel" to generate oxaloacetate to enhance the oxidation of acetyl-CoA through TCA cycle (McDonald et al. 2018). Both human and mouse RPE prefer to use proline to fuel their mitochondrial TCA cycle (Chao et al. 2017; Yam et al. 
2019). The addition of proline doubles the maximum $\mathrm{O}_{2}$ consumption compared to glucose alone in human RPE (Yam et al. 2019). This is consistent with reports in other species that proline can elicit maximal mitochondrial respiration (McDonald et al. 2018). However, the neural retina rarely uses proline directly for its mitochondrial metabolism (Yam et al. 2019). Its robust production of lactate and succinate may repress the activity of PRODH, and the hypoxic microenvironment can downregulate complex IV (Bisbach et al. 2020; Hancock et al. 2016; Kowaloff et al. 1977). These factors may make proline catabolism unfavorable in the neural retina. Nevertheless, the neural retina uses proline indirectly from the RPE, which exports proline-derived intermediates such as citrate, glutamate and aspartate towards the neural retina (Fig. 3).

What is the advantage of using proline as a metabolic substrate, especially in the RPE? First, proline has the highest solubility among the 20 amino acids, making it easy to store and transport (Bowden et al. 2018). It is 15-fold more soluble in aqueous solutions than glutamine, glutamate or branched chain amino acids. Second, proline synthesis is energetically expensive. Proline biosynthesis from glutamate or glutamine requires $2 \mathrm{NADPH}$ and $1 \mathrm{ATP}$, while proline biosynthesis from arginine or ornithine requires $1 \mathrm{NAD}(\mathrm{P})$ $\mathrm{H}$ (Fig. 2). NADPH is critical for energy metabolism and cellular antioxidant defense (Bradshaw 2019). RPE lives in a highly oxidative environment, demanding efficient NADPH supply to combat oxidative stress (Datta et al. 2017; Du et al. 2016). The uptake of proline can not only spare NADPH, but also result in the production of NADPH and glutathione (Fig. 4). Third, proline efficiently replenishes TCA cycle intermediates, despite the abundance of other substrates including glucose, lactate and fatty acids. Conventionally, these substrates enter the TCA cycle as acetyl-CoA which

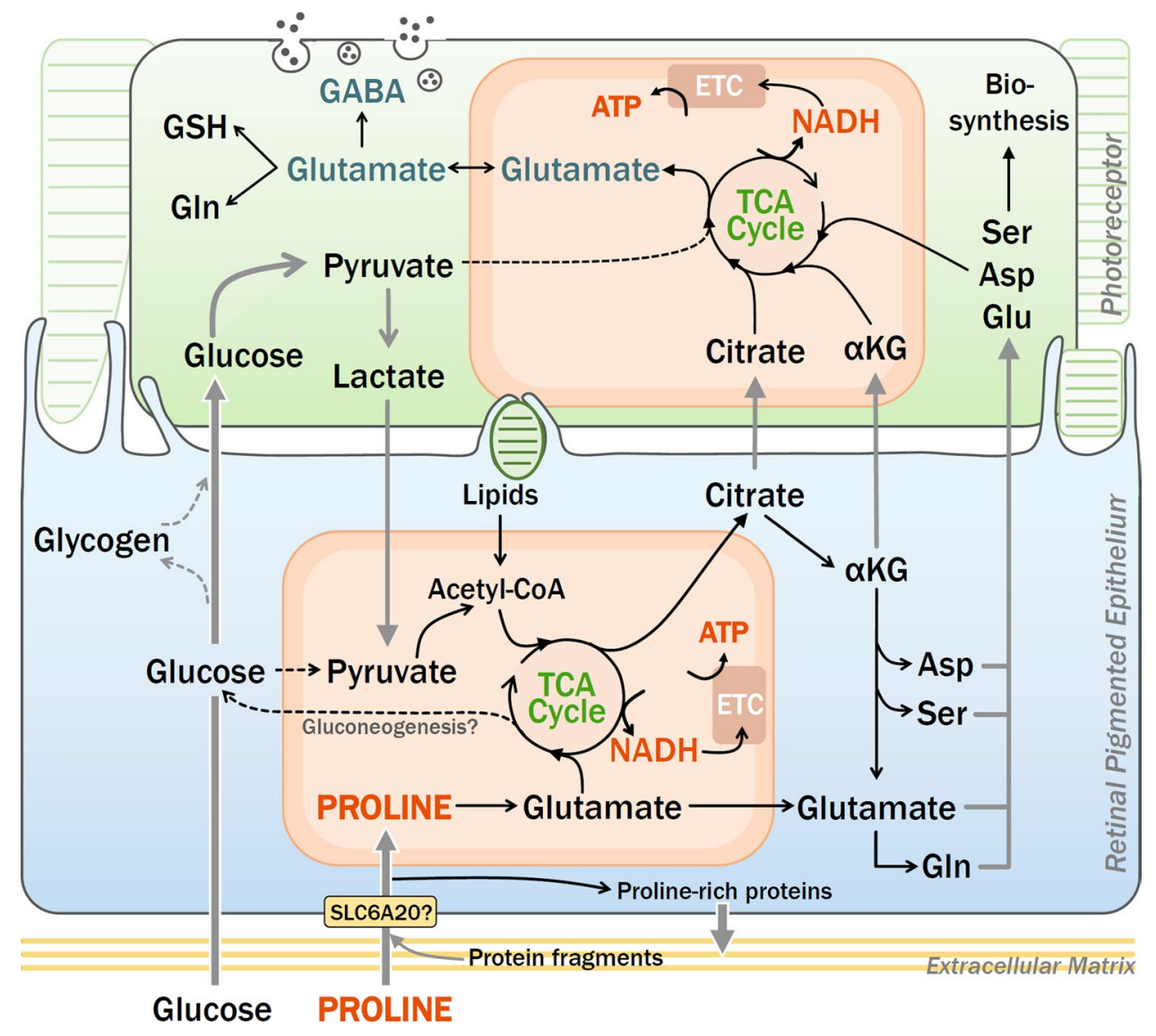

Fig. 3 RPE uses proline to fuel metabolism in both RPE and the retina. Blood glucose enters the RPE to be stored as small amounts of glycogen, and used minimally in the RPE mitochondrial metabolism. Most glucose is transported into the retina, which undergoes robust aerobic glycolysis to produce massive amounts of lactate. The exported lactate can be utilized by RPE as a fuel to preserve glucose for the retina. RPE also phagocytoses shed photoreceptor outer segments and degrades lipids to be used in the TCA cycle. Proline in the RPE serves as both a carbon source to replenish TCA cycle interme- diates, and as a nitrogen source to generate amino acids including glutamate and aspartate. These intermediates are exported in large amounts to fuel the TCA cycle in the retina, and support biosynthesis of lipids to replenish outer segments. Glutamate in the retina is an important neurotransmitter, and also the precursor for GABA, glutamine and GSH. $\alpha K G$ alpha-ketoglutarate, Asp aspartate, $G A B A$ gamma-aminobutyric acid, Gln glutamine, Glu glutamate, GSH glutathione, Ser serine 


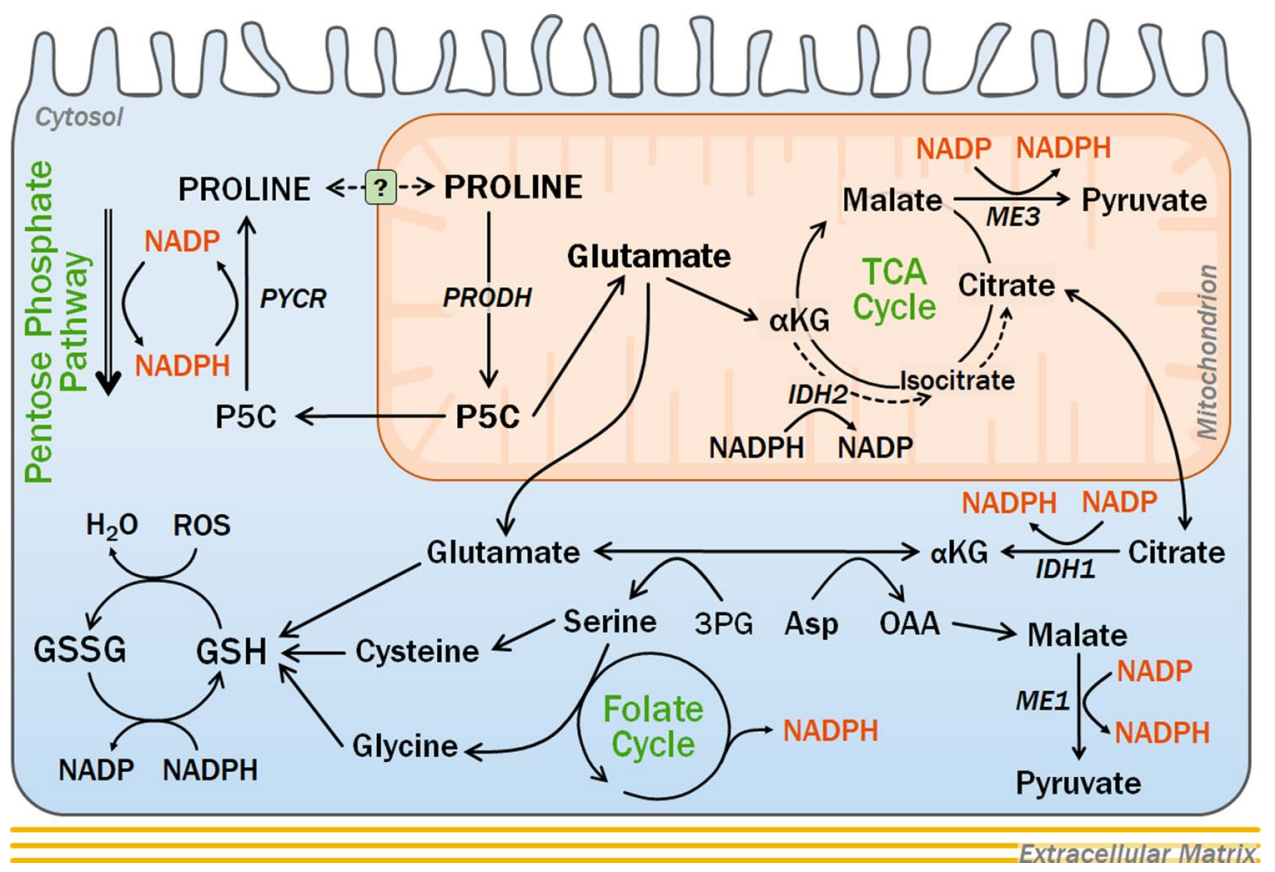

Fig. 4 Proline generates GSH and NADPH to counter oxidative stress. Proline can shuttle between the mitochondria and cytosol to form the proline cycle, which transfers electrons from NADPH into the mitochondria and stimulate flux of the pentose phosphate pathway. Proline catabolism can stimulate NADPH formation by driving malic enzymes, folate cycle and reductive carboxylation through IDH1/2. Glutamate, cysteine and glycine forms the tripeptide GSH, which is used by antioxidant enzymes to scavenge reactive oxygen

is mostly oxidized as $\mathrm{CO}_{2}$ and $\mathrm{H}_{2} \mathrm{O}$, and produces intermediates that leave the cycle (mitochondrial efflux) to support key biosynthetic pathways including synthesize of amino acids, fatty acids, or other nutrients (Fig. 3). To sustain the TCA cycle in the presence of fast influx and efflux, four or five carbon molecules are required to replenish the cycle, a process called anaplerosis. Stable isotope tracing studies show that proline-derived TCA cycle intermediates are exported to support retinal mitochondrial metabolism (Chao et al. 2017; Yam et al. 2019). Fourth, proline is an important nitrogen source. Our recent studies show that both human and mouse retinal explants preferentially uptake glutamate and aspartate, whereas proline could generate and release these amino acids to be used by the retina (Chao et al. 2017; $\mathrm{Li}$ et al. 2020). Glutamine is a common precursor for glutamate and aspartate; however, glutamine catabolism can also produce toxic free ammonia. Interestingly, when proline and other nutrients are available, RPE exports rather than consumes glutamine ( $\mathrm{Li}$ et al. 2020). In rat hepatocytes, proline produces glutamate and aspartate much faster than glutamine (Baquet et al. 1991). Finally, proline can increase the availability of glucose. Photoreceptors in the outer retina rely on glucose for its energy metabolism, which has to be transported across RPE (Kanow et al. 2017). The block of species (ROS) such as hydrogen peroxide $\left(\mathrm{H}_{2} \mathrm{O}_{2}\right)$. Oxidized glutathione (GSSG) is then reduced back to GSH by NADPH-dependent glutathione reductase, thereby consuming NADPH. 3PG 3-phosphoglycerate, $\alpha K G$ alpha-ketoglutarate, Asp aspartate, $I D H$ isocitrate dehydrogenase (isoforms 1,2), GSH glutathione, GSSG oxidized GSH, $M E$ malic enzyme (isoforms 1,3), OAA oxaloacetate, P5C pyrroline-5-carboxylate, $R O S$ reactive oxygen species

glucose transport or excessive glucose utilization in the RPE is sufficient to cause photoreceptor degeneration (Kurihara et al. 2016; Swarup et al. 2019). Lactate utilization in the RPE could similarly spare glucose for the photoreceptors (Kanow et al. 2017). Additionally, proline is also a known glucogenic amino acid and is used in supplements to maintain blood glucose during exercise (Nogusa et al. 2014). It was shown to potently stimulate glycogen synthesis in hepatocytes (Baquet et al. 1991; Bode et al. 1992). Glycogen is rapidly accumulated in cultured RPE after refeeding the media (Senanayake et al. 2006). Preferential proline uptake by the RPE may contribute to glycogenesis to support the high metabolic demand for glucose by photoreceptors.

\section{Proline generates glutathione and NADPH to protect against oxidative stress}

Glutathione (GSH) coupling with NADPH is the primary antioxidant system in mammalian cells (Forman et al. 2009). GSH is a tripeptide synthesized from glycine, glutamate and cysteine. Its regeneration from oxidized GSH (GSSG) requires NADPH. Inhibition of PRODH in human RPE substantially diminishes the amount of intracellular GSH and its precursors (Yam et al. 2019), indicating that proline is a 
critical component for GSH biosynthesis, likely by increasing the availability of glutamate, glycine and serine (a precursor for cysteine) in the RPE (Fig. 4). Consistently, proline has been shown to confer strong protection against oxidative damage in RPE and other cells in vitro (Krishnan et al. 2008; Natarajan et al. 2012). Multiple pathways contribute to NADPH production including the PPP, NADP-dependent IDH1/2, NADP-dependent malic enzyme, and serine-driven folate pathways (Fan et al. 2014) (Fig. 4). Key enzymes in these NADPH production pathways are highly enriched in the RPE compared to the neural retina in both humans and mice (Li et al. 2020). PPP is the classic pathway for NADPH production. However, a recent NADPH tracing study shows that serine-driven NADPH is comparable to PPP in cancer cells (Fan et al. 2014). We have reported that reductive carboxylation through IDH1/2 is highly active in human RPE cells, conferring RPE protection against oxidative damage (Du et al. 2016). Proline can activate PPP and NADPdependent malic enzymes, increase the flux of reductive carboxylation through IDH1/2, and stimulate serine metabolism in folate pathways (Allmann et al. 2013; Chao et al. 2017; Hagedorn and Phang 1986). Consequentially, dietary proline improves visual function in an RPE-specific oxidative damage mouse model (Yam et al. 2019). These protections may be attributed to the enhancement of the GSH and NADPH system through proline catabolism.

\section{Proline is specifically used in differentiated RPE}

Terminally-differentiated RPE is pigmented to reduce light damage in the tissue, contains tight junctions to form a blood-retinal barrier, and polarized to bidirectionally transport nutrients and waste products (Lakkaraju et al. 2020). Human RPE cells in culture typically take 4-6 weeks to adopt a polarized epithelial morphology. Interestingly, proline is the only nutrient whose consumption increases with RPE differentiation (Yam et al. 2019). Poorly-differentiated RPE cells including ARPE-19 cells and hRPE-1 cells, consume almost no proline as a nutrient (Yam et al. 2019). Consistently, the expression of SLC6A20 and PRODH are upregulated in RPE differentiation, whereas their expression is downregulated in de-differentiated RPE cells (Radeke et al. 2015). The dedifferentiation of RPE into a non-polarized fibroblast-like phenotype is commonly referred to as epithelial-to-mesenchymal transition (EMT). RPE with EMT can lose its normal function, contributing to retinal degenerative diseases such as AMD and proliferative vitreoretinopathy (PVR) (Zhou et al. 2020). Co-treatment with TGF- $\beta$ and TNF- $\alpha$ accelerates EMT in adult human RPE cells, which downregulates the transcripts of both SLC6A20 and PRODH more than 400 fold (Boles et al. 2020). The downregulation of PRODH by TGF- $\beta$ also occurs in renal and airway epithelial cells undergoing EMT (Brennan et al.
2012; Tian et al. 2015). An important feature in RPE differentiation is a reprogramming of metabolic dependency from glycolysis to mitochondrial oxidative phosphorylation (OXPHOS) (Agathocleous and Harris 2013; Zheng et al. 2016). OXPHOS genes and mitochondrial mass significantly increase during RPE differentiation (Iacovelli et al. 2016). Proline may efficiently fuel mitochondrial metabolism to meet the increased metabolic demand in differentiation. Either inhibition of mitochondrial OXPHOS or augmentation of glycolysis in RPE can result in dedifferentiation and loss of its epithelial properties (Adijanto and Philp 2014; Kurihara et al. 2016; Rosales et al. 2019; Zhao et al. 2011a). Inhibition of mitochondrial OXPHOS, particularly of complex III, blocks proline uptake in RPE, suggesting that the demand for proline catabolism is the driving force for the high proline utilization in differentiated RPE (Zhang et al. 2021).

\section{Proline metabolism in retinal diseases}

Mutations of genes involved in proline metabolism are associated with inherited retinal degenerations. A multitude of metabolomics studies on human plasma and vitreous samples repeatedly show that proline is among the most significantly altered metabolite in retinal degenerative diseases including AMD, proliferative vitreoretinopathy (PVR), diabetic retinopathy, and glaucoma (Table 2). We will focus on retinal diseases that are highly relevant to RPE dysfunction or degeneration in this review.

\section{Proline metabolism in inherited retinal degeneration}

Inherited retinal degenerations consist of a diverse group of retinal diseases characterized by progressive vision loss due to genetic mutations (Duncan et al. 2018). Inborn errors or genetic deficiency of several enzymes in proline synthesis result in inherited retinal degenerations. Patients with ALDH18Al (the gene encoding P5CS) mutations have retinal degeneration cutis laxa (loose skin), and fat pads (Wolthuis et al. 2014). Zebrafish carrying the pycrl gene deficiency show behavioral abnormalities, damaged RPE and retinal degeneration (Liang et al. 2019). Mutation of prolidase causes proline deficiency and chorioretinal atrophy in patients (Ogata et al. 1981). OAT deficiency causes gyrate atrophy, characterized by progressive and lobular loss of RPE/choroid and accumulation of ornithine in the plasma (Lodato et al. 1981; O'Donnell et al. 1978). Attempts to correct ornithine accumulation by dietary reduction of its precursor, arginine, show efficacy in halting the progression of retinal degeneration (Kaiser-Kupfer et al. 1991; Wang et al. 2000). The OAT deficiency causes over tenfold 
Table 2 Proline levels in retinal diseases

\begin{tabular}{|c|c|c|c|c|c|c|}
\hline Diseases & Species & Comparison $(n)$ & Samples & Fasting & Value* $(\mathrm{FC} / \mu \mathrm{M})$ & References \\
\hline \multirow[t]{4}{*}{ AMD } & Human & $\begin{array}{l}\text { AMD (314) } \\
\text { Control (82) }\end{array}$ & Plasma & Yes & $0.76(\mathrm{FC})$ & Lains et al. (2019) \\
\hline & Human & $\begin{array}{l}\text { Early/intermediate AMD (72) } \\
\text { Control (72) }\end{array}$ & Serum & No & AMD: 263.6 Control: 254.4 & Kersten et al. (2019) \\
\hline & Human & $\begin{array}{l}\text { Exudative-AMD (40) } \\
\text { Control (40) }\end{array}$ & Plasma & Yes & AMD: 191.2 Control: 165.4 & Chao de la Barca et al. (2020) \\
\hline & Human & $\begin{array}{l}\text { Wet AMD (26) } \\
\text { Control (20) }\end{array}$ & Aqueous humor & N/A & $0.04(\mathrm{FC})$ & Han et al. (2020) \\
\hline \multirow[t]{6}{*}{ DR } & Human & $\begin{array}{l}\text { PDR (20) } \\
\text { Control (31) }\end{array}$ & Vitreous & N/A & $3.3 \sim 5.7(\mathrm{FC})$ & Paris et al. (2016) \\
\hline & Human & $\begin{array}{l}\text { PDR (21) } \\
\text { Diabetic control (21) }\end{array}$ & Plasma & Yes & $0.52(\mathrm{FC})$ & Zhu et al. (2019) \\
\hline & Human & $\begin{array}{l}\text { PDR (9) } \\
\text { Control (8) }\end{array}$ & Vitreous & N/A & PDR: 25.2 Control: 6.6 & Haines et al. (2018) \\
\hline & Human & $\begin{array}{l}\text { PDR (28) } \\
\text { Control with macular hole (22) }\end{array}$ & Vitreous & N/A & $2.1(\mathrm{FC})$ & Wang et al. (2020) \\
\hline & Human & $\begin{array}{l}\text { DR (174) } \\
\text { Control (143) }\end{array}$ & Serum & N/A & $1.13 \sim 1.50(\mathrm{FC})$ & Yun et al. (2020) \\
\hline & Mouse & $\begin{array}{l}\text { OIR model (4) } \\
\text { Control (5) }\end{array}$ & Whole eye & N/A & $5.0(\mathrm{FC})$ & Paris et al. (2016) \\
\hline \multirow[t]{4}{*}{ Glaucoma } & Human & $\begin{array}{l}\text { POAG (36) } \\
\text { Control with cataract (27) }\end{array}$ & Plasma & Yes & POAG: 211.7 Control: 173.5 & Leruez et al. (2018) \\
\hline & Human & $\begin{array}{l}\text { PCG (45) } \\
\text { Control with ARC (10) }\end{array}$ & Aqueous humor & N/A & $5.27(\mathrm{FC})$ & Chen et al. (2019) \\
\hline & Human & $\begin{array}{l}\text { PCG (45) } \\
\text { Control with CC (10) }\end{array}$ & Aqueous humor & N/A & $5.68(\mathrm{FC})$ & Chen et al. (2019) \\
\hline & Human & $\begin{array}{l}\text { POAG (26) } \\
\text { Control with cataract (26) }\end{array}$ & Aqueous humor & Yes & POAG: 29.0 Control: 29.6 & Buisset et al. (2019) \\
\hline
\end{tabular}

*Value represents fold change (FC) of metabolite levels over control patients or absolute concentrations in $\mu \mathrm{M}$. $A M D$ age-related macular degeneration, $D R$ diabetic retinopathy, $P D R$ proliferative DR, $O I R$ oxygen-induced-retinopathy, $P O A G$ primary open-angle glaucoma, $P C G$ primary congenital glaucoma, $A R C$ age-related cataracts, $C C$ congenital cataracts

accumulation of ornithine in the plasma, which in vitro has been shown to inhibit P5CS (Hu et al. 1999). Excessive proline with normal ornithine in the urine is correlated with atypical gyrate atrophy in patients, suggesting that proline is deficient in the RPE (Hayasaka et al. 1982; Saito et al. 1981). Oral supplementation of ornithine significantly increases plasma proline in healthy controls but not in patients with gyrate atrophy. Deficiencies of OAT in both humans and mice support the idea that OAT proceeds in the direction of proline synthesis from ornithine in the adults but the opposite direction in neonates (de Sain-van der Velden et al. 2012; Wang et al. 1995). Inhibition of OAT in conjunction with ornithine administration could induce cytotoxicity in both bovine and human RPE, whereas supplementation with proline prevents this ornithine-induced cytotoxicity (Ando et al. 2000; Ueda et al. 1998). Still, there are few data on how these genetic mutations influence tissue proline levels and proline utilization in the RPE.

Proline is essential for the biosynthesis of collagen and the maintenance of ECM structure and composition (Karna et al. 2020; Van de Water and Galinovic-Schwartz 1986; Yoo et al. 1997). Mutations in the genes coding for ECM components are associated with retinal degeneration and choroidal neovascularization (Table 3). Mutations in the collagen 2A1, 9A1 and 11A1 result in Stickler syndrome, where affected individuals have ear, nose, throat and ophthalmologic abnormalities (Boysen et al. 2020; Kaarniranta et al. 2006; Nikopoulos et al. 2011), underscoring the importance of collagen structure on pathophysiology. Furthermore, mutations in ECM modulatory protein EFEMP1 lead to macular degeneration with subretinal deposits (Stone et al. 1999). TIMP-1 and -3 are secreted by RPE cells for regulation of MMP activity. TIMP-3 has the broadest inhibition spectrum and is tightly bound to the BrM in the human retina (Fariss et al. 1997). Mutations of the TIMP3 gene result in Sorsby fundus dystrophy (SFD), a rare autosomal dominant inherited retinal degeneration that shares several similar clinical features with AMD including sub-RPE deposits, geography atrophy, and choroidal neovascularization (Anand-Apte et al. 2019; Weber et al. 1994). Mutant TIMP-3 was later found 
Table 3 Genetic mutations in ECM components that causes retinal pathology

\begin{tabular}{|c|c|c|c|c|}
\hline Gene & Genetic disease & Retinal features & Species & References \\
\hline \multirow[t]{2}{*}{ COL2A1 } & Stickler syndrome, type I & $\begin{array}{l}\text { Membraneous vitreous } \\
\text { Retinal detachment } \\
\text { Paravascular pigmented lattice degeneration }\end{array}$ & $\begin{array}{l}\text { Human } \\
\text { Mouse }\end{array}$ & $\begin{array}{l}\text { Ballo et al. (1998); Richards et al. (2000); Go } \\
\text { et al. (2003); Kaarniranta et al. (2006) }\end{array}$ \\
\hline & $\begin{array}{l}\text { Epiphyseal Dysplasia, } \\
\text { Multiple, with Myopia } \\
\text { and Conductive Deafness }\end{array}$ & $\begin{array}{l}\text { Asteroid hyalosis } \\
\text { Retinal thinning }\end{array}$ & Human & Beighton et al. (1978) \\
\hline COL9A1 & Stickler syndrome, type IV & $\begin{array}{l}\text { Chorioretinal degeneration } \\
\text { Retinal detachment }\end{array}$ & Human & $\begin{array}{l}\text { Van Camp et al. (2006); Nikopoulos et al. } \\
\text { (2011) }\end{array}$ \\
\hline COL11A1 & $\begin{array}{l}\text { Stickler syndrome, type II } \\
\text { Marshall syndrome }\end{array}$ & $\begin{array}{l}\text { Beaded vitreous } \\
\text { Retinal detachment } \\
\text { Paravascular pigmented lattice degeneration }\end{array}$ & Human & $\begin{array}{l}\text { Annunen et al. (1999); Richards et al. (1996); } \\
\text { Boysen et al. (2020) }\end{array}$ \\
\hline C1QTNF5 & $\begin{array}{l}\text { Macular dystrophy, } \\
\text { late onset }\end{array}$ & $\begin{array}{l}\text { Macular degeneration } \\
\text { Chorioretinal atrophy } \\
\text { Choroidal neovascularization }\end{array}$ & $\begin{array}{l}\text { Human } \\
\text { Mouse }\end{array}$ & $\begin{array}{l}\text { Hayward et al. (2003); Ayyagari et al. (2005); } \\
\text { Borooah et al. (2009); Shu et al. (2011); } \\
\text { Chavali et al. (2011) }\end{array}$ \\
\hline TIMP3 & Sorsby fundus dystrophy & $\begin{array}{l}\text { Subretinal neovascularization } \\
\text { Central macular lesion } \\
\text { Chorioretinal atrophy } \\
\text { Retinal pigment epithelial atrophy } \\
\text { Geographic atrophy }\end{array}$ & $\begin{array}{l}\text { Human } \\
\text { Mouse }\end{array}$ & $\begin{array}{l}\text { Weber et al. (1994); Langton et al. (2000); } \\
\text { Gliem et al. (2015); Weber et al. (2002) }\end{array}$ \\
\hline EFEMP1 & $\begin{array}{l}\text { Doyne honeycomb retinal } \\
\text { degeneration (Malattia } \\
\text { Leventinese) }\end{array}$ & $\begin{array}{l}\text { Radial drusen } \\
\text { Geographic atrophy } \\
\text { Abnormal retinal pigmentation } \\
\text { Choroidal neovascularization }\end{array}$ & $\begin{array}{l}\text { Human } \\
\text { Mouse }\end{array}$ & $\begin{array}{l}\text { Stone et al. (1999); Kermani et al. (1999); } \\
\text { Tarttelin et al. (2001); Fu et al. (2007) }\end{array}$ \\
\hline
\end{tabular}

to be secreted at elevated levels by RPE cells, albeit having decreased inhibition on MMPs (Engel et al. 2021, bioRxiv). Consequentially, iPSC-derived RPE cells from SFD patients have increased intracellular levels of 4-hydroxyproline, indicating enhanced ECM degradation. Degradation of ECM not only releases bound growth factors that can induce a response from RPE cells, MMP cleavage also produces short bioactive fragments called matrikines (Patel and Snelgrove 2018). Tripeptide Pro-Gly-Pro was demonstrated in other tissues to have the capacity to regulate processes including proliferation and migration (Ma et al. 2011), angiogenesis (Monboisse et al. 2014) and chemotaxis (Karsdal et al. 2015). How matrikines affect RPE metabolism and the outer retinal environment has not yet been investigated.

\section{Proline metabolism in AMD}

AMD, the leading cause of irreversible central blindness in the elderly population, is characterized by drusen deposits, geographic atrophy, and choroidal neovascularization. The causes of AMD have been attributed to a multitude of environmental and genetic factors, with aging being the major risk (Datta et al. 2017; Handa et al. 2019). RPE dysfunction due to impaired mitochondrial metabolism, oxidative stress, aging and inflammation, is thought to underlie the pathogenesis of AMD (Ferrington et al. 2020). Inhibition of mitochondrial metabolism, specifically in RPE, is sufficient to induce AMD-like retinal degeneration in mice (Kurihara et al. 2016; Rosales et al. 2019; Zhao et al. 2011a). RPE cells from AMD donors have impaired mitochondrial metabolism (Ferrington et al. 2017; Golestaneh et al. 2016). Patients with an $\mathrm{A} 3243 \mathrm{G}$ point mutation in mitochondrial DNA have RPE atrophy, subretinal deposits, and maculopathy (Daruich et al. 2014; Fung et al. 2013; Smith et al. 1999). Altered mitochondrial metabolism is a metabolic signature of aging RPE and retina (Wang et al. 2018). The inhibition of mitochondrial metabolism in human RPE culture can block proline utilization and markedly reduce the secretion of intermediates and amino acids to support the neural retina (Zhang et al. 2021). In aging mice, plasma proline levels are reduced (Seo et al. 2016). Multiple metabolomics studies identified significant changes in proline in AMD patients (Hou et al. 2020) (Table 2). A recent targeted-metabolomics study also found proline to be one of six significantly changed metabolites among the 188 metabolites analyzed in the plasma of AMD patients (Chao de la Barca et al. 2020). Additionally, SLC6A20 is one of the most significant new loci linked to AMD from GWAS (Gao et al. 2019), while SLC6A20 expression is reported to be downregulated in retinas from AMD donors (Ratnapriya et al. 2019). Likewise, a transcriptome database shows that P5CS is significantly downregulated in RPE from both dry and wet AMD donors (Newman et al. 2012).

Oxidative damage is another major cause of RPE dysfunction in AMD (Cai et al. 2000). Under conditions of oxidative stress, cellular GSH concentrations are markedly 
reduced due to a combination of enhanced degradation and decreased synthesis (Wu et al. 2004). Supplementation of GSH precursors protects RPE from oxidative damage (Kularatne et al. 2020; Terluk et al. 2019). The deficiency of Nrf2, a transcription factor in the GSH system, results in drusen-like deposits similar to AMD in mice. (Zhao et al. 2011b). We have found that inhibition of reductive carboxylation disrupts the redox balance and increases the sensitivity of cultured RPE cells to oxidative damage. Supporting reductive carboxylation protects RPE cell viability from oxidative stress (Du et al. 2016). Proline is sufficient to increase reductive carboxylation, promote GSH synthesis and regeneration, and protect RPE against oxidative damage.

ECM remodeling resulting from RPE dysfunction plays an important role in AMD pathogenesis. The collagenrich BrM can be three-fold thicker with reduced elasticity in AMD (Nita et al. 2014b) as a result of reduced solubility and increased cross-linking with specific biomolecules (Eamegdool et al. 2020; Nita et al. 2014b). Basal laminar deposits and drusen are hallmarks of aging and early AMD (Bhutto and Lutty 2012; Fernandez-Godino et al. 2016, 2018). ECM proteins including collagen, MMPs and TIMP3, are key components within these deposits, and ECM dysregulation may play a role in the AMD-like macular degeneration seen in patients with TIMP3 and EFEMP1 mutations (Anand-Apte et al. 2019; Hulleman 2016) (Table 3). Autoradiographic studies of aged primate and human retina with ${ }^{3} \mathrm{H}$ proline show that the rate of ECM turnover is much slower in the regions with drusen and basal deposits (Hirata and Feeney-Burns 1992). Local ECM degradation supplies proline to tissues or cells, which is especially important under conditions of oxidative stress (Pandhare et al. 2009). It remains to be determined whether proline utilization is impaired in AMD.

\section{Proline metabolism in Proliferative Vitreoretinopathy (PVR)}

PVR is one of the most common and severe complications following the treatment of rhegmatogenous retinal detachment, resulting in poor visual outcomes (Idrees et al. 2019). PVR is characterized by the formation of scar-like fibrocellular membranes in the vitreous cavity and surfaces of the retina. These fibrocellular membranes are composed of excessive ECM and RPE cells that have undergone EMT, which can contract to result in retinal folds, re-detachment, and vision loss (Hiscott et al. 1999; Idrees et al. 2019). The dedifferentiation of RPE cells into fibroblast-like cells through EMT due to exposure to growth factors and cytokines is pivotal in the pathogenesis of PVR. These de-differentiated cells migrate to retinal surfaces, producing collagen (mostly type I), MMPs, fibronectin and TIMPs to rebuild the ECM (Greene et al. 2017; Hiscott et al. 1999). Treatment of human RPE with growth factors or cytokines could induce EMT and substantially increases type I collagen synthesis (Boles et al. 2020; Itoh et al. 2007; Jing et al. 2019). The proline analog, cis-hydroxyproline, inhibits collagen synthesis, attachment and migration of bovine RPE cells in dose- and time-dependent manner (Yoo et al. 1997). In a rabbit PVR model, cis-hydroxyproline significantly reduces the rate of retinal detachment (Radtke et al. 1986; Yasukawa et al. 2002). Epithelial cells including RPE that has undergone EMT can suppress the expression of PRODH (Boles et al. 2020; Brennan et al. 2012; Tian et al. 2015). These studies suggest that RPE in PVR may have altered proline metabolism, shifting from proline catabolism to collagen synthesis.

\section{Conclusion and perspectives}

Proline transport and metabolism emerge as important regulators in retinal physiology and diseases through modulating mitochondrial metabolism, ROS protection, ECM remodeling and cell differentiation. However, except for transcriptomics data, there is a lack of information on the expression and localization of proline transporters and key enzymes in proline metabolism in normal and diseased retinas. Furthermore, there is scarce data on proline levels in the RPE and neural retinas in retinal disease models. Performing loss-of-function experiments specifically in RPE for genes in proline metabolism will provide important insights on the roles of proline in retinal health and diseases. These genetically deficient models will also be useful tools to investigate metabolic communications between RPE and the neural retinas. SLC6A20 and PRODH are downregulated in RPE with EMT and AMD, which could make them potential therapeutic targets for PVR and AMD.

Acknowledgements National Institutes of Health Grant EY026030 (JRC and JD) and EY031324 (JD), BrightFocus Foundation M2020141 (JD) and M2020217 (JRC), Research for Prevention of Blindness (JRC), Alcon Research Institute (JRC) and the Retina Research Foundation (JD) supported this work. We are grateful to Dr. James B. Hurley for his critical reading of the manuscript.

\section{Declarations}

Conflict of interest The authors declare no conflicts of interest.

Ethical approval This article reviews published studies and does not require either the approval of animal use or human consent.

Informed consent No informed consent is required for this study.

\section{References}

Adijanto J, Philp NJ (2014) Cultured primary human fetal retinal pigment epithelium (hfRPE) as a model for evaluating RPE metabolism. Exp Eye Res 126:77-84. https://doi.org/10.1016/j.exer. 2014.01.015 
Adijanto J, Du J, Moffat C, Seifert EL, Hurle JB, Philp NJ (2014) The retinal pigment epithelium utilizes fatty acids for ketogenesis. J Biol Chem 289:20570-20582. https://doi.org/10.1074/jbc. M114.565457

Agathocleous M, Harris WA (2013) Metabolism in physiological cell proliferation and differentiation. Trends Cell Biol 23:484-492. https://doi.org/10.1016/j.tcb.2013.05.004

Albers A et al (2001) Na+ transport by the neural glutamine transporter ATA1. Pflugers Archiv : Eur J Physiol 443:92-101. https://doi.org/10.1007/s004240100663

Allmann S et al (2013) Cytosolic NADPH homeostasis in glucosestarved procyclic Trypanosoma brucei relies on malic enzyme and the pentose phosphate pathway fed by gluconeogenic flux. J Biol Chem 288:18494-18505. https://doi.org/10.1074/jbc. M113.462978

Anand-Apte B, Chao JR, Singh R, Stohr H (2019) Sorsby fundus dystrophy: Insights from the past and looking to the future. J Neurosci Res 97:88-97. https://doi.org/10.1002/jnr.24317

Ando A, Ueda M, Uyama M, Masu Y, Okumura T, Ito S (2000) Heterogeneity in ornithine cytotoxicity of bovine retinal pigment epithelial cells in primary culture. Exp Eye Res 70:89-96. https://doi.org/10.1006/exer.1999.0750

Annunen S et al (1999) Splicing mutations of 54-bp exons in the COL11A1 gene cause Marshall syndrome, but other mutations cause overlapping Marshall/Stickler phenotypes. Am J Human Genet 65:974-983. https://doi.org/10.1086/302585

Arrese EL, Soulages JL (2010) Insect fat body: energy, metabolism, and regulation. Ann Review Entomol 55:207-225. https://doi. org/10.1146/annurev-ento-112408-085356

Atlante A, Passarella S, Pierro P, Quagliariello E (1994) Proline transport in rat kidney mitochondria. Arch Biochem Biophys 309:139-148. https://doi.org/10.1006/abbi.1994.1096

Ayyagari R et al (2005) Late-onset macular degeneration and long anterior lens zonules result from a CTRP5 gene mutation. Invest Ophthalmol Visual Sci 46:3363-3371. https://doi.org/ 10.1167/iovs.05-0159

Ballo R, Beighton PH, Ramesar RS (1998) Stickler-like syndrome due to a dominant negative mutation in the COL2A1 gene. Am J Med Genet 80:6-11. https://doi.org/10.1002/(sici)10968628(19981102)80:1\%3c6::aid-ajmg2\%3e3.0.co;2-0

Baquet A, Lavoinne A, Hue L (1991) Comparison of the effects of various amino acids on glycogen synthesis, lipogenesis and ketogenesis in isolated rat hepatocytes. Biochem J 273(Pt 1):57-62. https://doi.org/10.1042/bj2730057

Baumgartner MR et al (2000) Hyperammonemia with reduced ornithine, citrulline, arginine and proline: a new inborn error caused by a mutation in the gene encoding delta(1)-pyrroline5-carboxylate synthase. Human Mol Genet 9:2853-2858. https://doi.org/10.1093/hmg/9.19.2853

Baumgartner MR et al (2005) Delta1-pyrroline-5-carboxylate synthase deficiency: neurodegeneration, cataracts and connective tissue manifestations combined with hyperammonaemia and reduced ornithine, citrulline, arginine and proline. Eur J Pediatrics 164:31-36. https://doi.org/10.1007/s00431-004-1545-3

Beighton P, Goldberg L, Hof JO (1978) Dominant inheritance of multiple epiphyseal dysplasia, myopia and deafness. Clin Genet 14:173-177. https://doi.org/10.1111/j.1399-0004.1978. tb02125.x

Bennis A, Gorgels TG, Ten Brink JB, van der Spek PJ, Bossers K, Heine VM, Bergen AA (2015) Comparison of mouse and human retinal pigment epithelium gene expression profiles: potential implications for age-related macular degeneration. PLoS ONE 10:e0141597. https://doi.org/10.1371/journal.pone.0141597

Bhutto I, Lutty G (2012) Understanding age-related macular degeneration (AMD): relationships between the photoreceptor/retinal pigment epithelium/Bruch's membrane/choriocapillaris complex.
Mol Aspects Med 33:295-317. https://doi.org/10.1016/j.mam. 2012.04.005

Bisbach CM, Hass DT, Robbings BM, Rountree AM, Sadilek M, Sweet IR, Hurley JB (2020) Succinate can shuttle reducing power from the hypoxic retina to the $\mathrm{O} 2$-rich pigment epithelium. Cell Rep 31:107606. https://doi.org/10.1016/j.celrep. 2020.107606

Bode AM, Foster JD, Nordlie RC (1992) Glyconeogenesis from L-proline involves metabolite inhibition of the glucose-6-phosphatase system. J Biol Chem 267:2860-2863

Boles NC et al (2020) Epigenomic and transcriptomic changes during human RPE EMT in a stem cell model of epiretinal membrane pathogenesis and prevention by nicotinamide. Stem Cell Rep 14:631-647. https://doi.org/10.1016/j.stemcr.2020.03.009

Borooah S, Collins C, Wright A, Dhillon B (2009) Late-onset retinal macular degeneration: clinical insights into an inherited retinal degeneration. Br J Ophthalmol 93:284-289. https://doi.org/10. 1136/bjo.2008.150151

Bowden NA, Sanders JPM, Bruins ME (2018) Solubility of the proteinogenic alpha-amino acids in water, ethanol, and ethanolwater mixtures. J Chem Eng Data 63:488-497. https://doi.org/ 10.1021/acs.jced.7b00486

Boysen KB, La Cour M, Kessel L (2020) Ocular complications and prophylactic strategies in Stickler syndrome: a systematic literature review. Ophthalmic Genet 41:223-234. https://doi.org/ 10.1080/13816810.2020.1747092

Bradshaw PC (2019) Cytoplasmic and mitochondrial NADPHcoupled redox systems in the regulation of aging. Nutrients. https://doi.org/10.3390/nu11030504

Brennan EP et al (2012) Next-generation sequencing identifies TGF-beta1-associated gene expression profiles in renal epithelial cells reiterated in human diabetic nephropathy. Biochim Biophys Acta 1822:589-599. https://doi.org/10.1016/j.bbadis. 2012.01.008

Broer S (2006) The SLC6 orphans are forming a family of amino acid transporters. Neurochem Int 48:559-567. https://doi.org/ 10.1016/j.neuint.2005.11.021

Broer A, Balkrishna S, Kottra G, Davis S, Oakley A, Broer S (2009) Sodium translocation by the iminoglycinuria associated imino transporter (SLC6A20). Mol Membrane Biol 26:333-346. https://doi.org/10.1080/09687680903150027

Cai J, Nelson KC, Wu M, Sternberg P Jr, Jones DP (2000) Oxidative damage and protection of the RPE. Prog Retin Eye Res 19:205-221. https://doi.org/10.1016/s1350-9462(99)00009-9

Camargo SMR, Vuille-Dit-Bille RN, Meier CF, Verrey F (2020) ACE2 and gut amino acid transport. Clin Sci (Lond) 134:28232833. https://doi.org/10.1042/CS20200477

Campochiaro PA, Jerdon JA, Glaser BM (1986) The extracellular matrix of human retinal pigment epithelial cells in vivo and its synthesis in vitro. Invest Ophthalmol Visual Sci 27:1615-1621

Cao G, Chen Y, Zhang J, Liu Y, Zhang M, Zhang K, Su Z (2015) Effects of adiponectin polymorphisms on the risk of advanced age-related macular degeneration. Biomarkers: Biochem Indicators Exposure, Response, Susceptibility Chemicals 20:266270. https://doi.org/10.3109/1354750X.2015.1068857

Chao JR et al (2017) Human retinal pigment epithelial cells prefer proline as a nutrient and transport metabolic intermediates to the retinal side. J Biol Chem 292:12895-12905. https://doi.org/ 10.1074/jbc.M117.788422

Chao de la Barca JM et al (2020) A plasma metabolomic profiling of exudative age-related macular degeneration showing carnosine and mitochondrial deficiencies. J Clin Med. https://doi.org/10. 3390/jcm9030631

Chavali VR, Khan NW, Cukras CA, Bartsch DU, Jablonski MM, Ayyagari R (2011) A CTRP5 gene S163R mutation knock-in 
mouse model for late-onset retinal degeneration. Human Mol Genet 20:2000-2014. https://doi.org/10.1093/hmg/ddr080

Cunningham DF, O'Connor B (1997) Proline specific peptidases. Biochim Biophys Acta 1343:160-186. https://doi.org/10.1016/ s0167-4838(97)00134-9

Curino AC et al (2005) Intracellular collagen degradation mediated by uPARAP/Endo 180 is a major pathway of extracellular matrix turnover during malignancy. J Cell Biol 169:977-985. https://doi. org/10.1083/jcb.200411153

Daruich A, Matet A, Borruat FX (2014) Macular dystrophy associated with the mitochondrial DNA A3243G mutation: pericentral pigment deposits or atrophy? Report of two cases and review of the literature. BMC Ophthalmol 14:77. https://doi.org/10.1186/ 1471-2415-14-77

Datta S, Cano M, Ebrahimi K, Wang L, Handa JT (2017) The impact of oxidative stress and inflammation on RPE degeneration in non-neovascular AMD. Prog Retin Eye Res 60:201-218. https:// doi.org/10.1016/j.preteyeres.2017.03.002

De Ingeniis J et al (2012) Functional specialization in proline biosynthesis of melanoma. PLoS ONE 7:e45190. https://doi.org/10. 1371/journal.pone.0045190

de Sain-van der Velden MG et al (2012) The proline/citrulline ratio as a biomarker for OAT deficiency in early infancy. JIMD Rep 6:95-99. https://doi.org/10.1007/8904_2011_122

Dominguez JM 2nd et al (2016) Adeno-associated virus overexpression of angiotensin-converting enzyme- 2 reverses diabetic retinopathy in type 1 diabetes in mice. Am J Pathol 186:1688-1700. https:// doi.org/10.1016/j.ajpath.2016.01.023

Du J et al (2013) Cytosolic reducing power preserves glutamate in retina. Proc Natl Acad Sci USA 110:18501-18506. https://doi. org/10.1073/pnas.1311193110

Du J et al (2016) Reductive carboxylation is a major metabolic pathway in the retinal pigment epithelium. Proc Natl Acad Sci USA 113:14710-14715. https://doi.org/10.1073/pnas.1604572113

Dunaevsky YE, Tereshchenkova VF, Oppert B, Belozersky MA, Filippova IY, Elpidina EN (2020) Human proline specific peptidases: a comprehensive analysis. Biochim Biophys Acta General Subjects 1864:129636. https://doi.org/10.1016/j.bbagen.2020. 129636

Duncan JL et al (2018) Inherited retinal degenerations: current landscape and knowledge gaps. Trans Vision Sci Technol 7:6. https:// doi.org/10.1167/tvst.7.4.6

Eamegdool SS, Sitiwin EI, Cioanca AV, Madigan MC (2020) Extracellular matrix and oxidative stress regulate human retinal pigment epithelium growth. Free Radical Biol Med 146:357-371. https:// doi.org/10.1016/j.freeradbiomed.2019.11.018

Ellinghaus D et al (2020) Genomewide association study of severe covid-19 with respiratory failure. New England J Med 383:15221534. https://doi.org/10.1056/NEJMoa2020283

Fan J, Ye J, Kamphorst JJ, Shlomi T, Thompson CB, Rabinowitz JD (2014) Quantitative flux analysis reveals folate-dependent NADPH production. Nature 510:298-302. https://doi.org/10. 1038/nature13236

Fariss RN, Apte SS, Olsen BR, Iwata K, Milam AH (1997) Tissue inhibitor of metalloproteinases-3 is a component of Bruch's membrane of the eye. Am J Pathol 150:323-328

Fernandez-Godino R, Pierce EA, Garland DL (2016) Extracellular matrix alterations and deposit formation in AMD. Adv Exp Med Biol 854:53-58. https://doi.org/10.1007/978-3-319-17121-0_8

Fernandez-Godino R, Bujakowska KM, Pierce EA (2018) Changes in extracellular matrix cause RPE cells to make basal deposits and activate the alternative complement pathway. Hum Mol Genet 27:147-159. https://doi.org/10.1093/hmg/ddx392

Ferrington DA et al (2017) Altered bioenergetics and enhanced resistance to oxidative stress in human retinal pigment epithelial cells from donors with age-related macular degeneration. Redox Biol 13:255-265. https://doi.org/10.1016/j.redox.2017.05.015

Ferrington DA, Fisher CR, Kowluru RA (2020) Mitochondrial defects drive degenerative retinal diseases. Trends Mol Med 26:105-118. https://doi.org/10.1016/j.molmed.2019.10.008

Forman HJ, Zhang H, Rinna A (2009) Glutathione: overview of its protective roles, measurement, and biosynthesis. Mol Aspects Med 30:1-12. https://doi.org/10.1016/j.mam.2008.08.006

Fu L et al (2007) The R345W mutation in EFEMP1 is pathogenic and causes AMD-like deposits in mice. Human Mol Genet 16:24112422. https://doi.org/10.1093/hmg/ddm198

Fu X, Lin R, Qiu Y, Yu P, Lei B (2017) Overexpression of angiotensinconverting enzyme 2 ameliorates amyloid beta-induced inflammatory response in human primary retinal pigment epithelium. Invest Ophthalmol Visual Sci 58:3018-3028. https://doi.org/10. 1167/iovs.17-21546

Fung AT, Engelbert M, Odel JG, Yannuzzi LA (2013) Subretinal deposits, paramacular atrophy and pigmentary retinopathy in mitochondrial encephalopathy, lactic acidosis, and stroke-like episodes. Retinal Cases Brief Rep 7:14-18. https://doi.org/10. 1097/ICB.0b013e318271ee90

Gao XR, Huang H, Kim H (2018) Genome-wide association analyses identify 139 loci associated with macular thickness in the UK Biobank cohort. Human Mol Genet. https://doi.org/10.1093/ hmg/ddy 422

Gao XR, Huang H, Kim H (2019) Genome-wide association analyses identify 139 loci associated with macular thickness in the UK Biobank cohort. Human Mol Genet 28:1162-1172. https://doi. org/10.1093/hmg/ddy422

Garcia-Onrubia L, Valentin-Bravo FJ, Coco-Martin RM, GonzalezSarmiento R, Pastor JC, Usategui-Martin R, Pastor-Idoate S (2020) Matrix metalloproteinases in age-related macular degeneration (AMD). Int J Mol Sci. https://doi.org/10.3390/ijms2 1165934

Gliem M et al (2015) Sorsby fundus dystrophy: novel mutations novel phenotypic characteristics, and treatment outcomes. Invest Ophthalmol Visual Sci 56:2664-2676. https://doi.org/10.1167/iovs. 14-15733

Go SL, Maugeri A, Mulder JJ, van Driel MA, Cremers FP, Hoyng CB (2003) Autosomal dominant rhegmatogenous retinal detachment associated with an Arg453Ter mutation in the COL2A1 gene. Invest Ophthalmol Visual Sci 44:4035-4043. https://doi.org/10. 1167/iovs.02-0736

Golestaneh N, Chu Y, Cheng SK, Cao H, Poliakov E, Berinstein DM (2016) Repressed SIRT1/PGC-1alpha pathway and mitochondrial disintegration in iPSC-derived RPE disease model of agerelated macular degeneration. J Trans Med 14:344. https://doi. org/10.1186/s12967-016-1101-8

Greene WA, Burke TA, Kaini RR, Por ED, Wang HC (2017) Polarized secretion of matrix metalloproteinases and their inhibitors by retinal pigment epithelium derived from induced pluripotent stem cells during wound healing. J Ocular Pharmacol Therapeutics: Off J Assoc Ocular Pharmacol Ther 33:132-140. https://doi.org/ 10.1089/jop.2016.0070

Hagedorn CH, Phang JM (1986) Catalytic transfer of hydride ions from NADPH to oxygen by the interconversions of proline and delta 1-pyrroline-5-carboxylate. Arch Biochem Biophys 248:166-174. https://doi.org/10.1016/0003-9861(86)90413-3

Hagglund MG et al (2013) Characterization of the transporterB0AT3 (Slc6a17) in the rodent central nervous system. BMC Neurosci 14:54. https://doi.org/10.1186/1471-2202-14-54

Hancock CN, Liu W, Alvord WG, Phang JM (2016) Co-regulation of mitochondrial respiration by proline dehydrogenase/oxidase and succinate. Amino Acids 48:859-872. https://doi.org/10.1007/ s00726-015-2134-7 
Handa JT et al (2019) A systems biology approach towards understanding and treating non-neovascular age-related macular degeneration. Nat Commun 10:3347. https://doi.org/10.1038/ s41467-019-11262-1

Hatanaka T, Huang W, Wang H, Sugawara M, Prasad PD, Leibach FH, Ganapathy V (2000) Primary structure, functional characteristics and tissue expression pattern of human ATA2, a subtype of amino acid transport system A. Biochim Biophys Acta 1467:1-6. https://doi.org/10.1016/s0005-2736(00)00252-2

Hatanaka T, Huang W, Ling R, Prasad PD, Sugawara M, Leibach FH, Ganapathy V (2001) Evidence for the transport of neutral as well as cationic amino acids by ATA3, a novel and liver-specific subtype of amino acid transport system A. Biochim Biophys Acta 1510:10-17. https://doi.org/10.1016/s0005-2736(00)00390-4

Hayasaka S, Mizuno K, Yabata K, Saito T, Tada K (1982) Atypical gyrate atrophy of the choroid and retina associated with iminoglycinuria. Arch Ophthalmol 100:423-425

Hayward C et al (2003) Mutation in a short-chain collagen gene, CTRP5, results in extracellular deposit formation in late-onset retinal degeneration: a genetic model for age-related macular degeneration. Human Mol Genet 12:2657-2667. https://doi.org/ $10.1093 / \mathrm{hmg} / \mathrm{ddg} 289$

Hirata A, Feeney-Burns L (1992) Autoradiographic studies of aged primate macular retinal pigment epithelium. Invest Ophthalmol Visual Sci 33:2079-2090

Hiscott P, Sheridan C, Magee RM, Grierson I (1999) Matrix and the retinal pigment epithelium in proliferative retinal disease. Prog Retin Eye Res 18:167-190. https://doi.org/10.1016/s13509462(98)00024-X

Hou XW, Wang Y, Pan CW (2020) Metabolomics in age-related macular degeneration: a systematic review. Invest Ophthalmol Visual Sci 61:13. https://doi.org/10.1167/iovs.61.14.13

Hu CA, Lin WW, Obie C, Valle D (1999) Molecular enzymology of mammalian Delta1-pyrroline-5-carboxylate synthase. Alternative splice donor utilization generates isoforms with different sensitivity to ornithine inhibition. J Biol Chem 274:6754-6762

Hulleman JD (2016) Malattia leventinese/doyne honeycomb retinal dystrophy: similarities to age-related macular degeneration and potential therapies. Adv Exp Med Biol 854:153-158. https://doi. org/10.1007/978-3-319-17121-0_21

Hurley JB, Lindsay KJ, Du J (2015) Glucose, lactate, and shuttling of metabolites in vertebrate retinas. J Neurosci Res 93:1079-1092. https://doi.org/10.1002/jnr.23583

Iacovelli J, Rowe GC, Khadka A, Diaz-Aguilar D, Spencer C, Arany Z, Saint-Geniez M (2016) PGC-1alpha induces human RPE oxidative metabolism and antioxidant capacity. Invest Ophthalmol Visual Sci 57:1038-1051. https://doi.org/10.1167/iovs.15-17758

Idrees S, Sridhar J, Kuriyan AE (2019) Proliferative vitreoretinopathy: a review. Int Ophthalmol Clin 59:221-240. https://doi.org/10. 1097/IIO.0000000000000258

Itoh Y, Kimoto K, Imaizumi M, Nakatsuka K (2007) Inhibition of RhoA/Rho-kinase pathway suppresses the expression of type I collagen induced by TGF-beta2 in human retinal pigment epithelial cells. Exp Eye Res 84:464-472. https://doi.org/10.1016/j. exer.2006.10.017

Jensen A, Figueiredo-Larsen M, Holm R, Broberg ML, Brodin B, Nielsen CU (2014) PAT1 (SLC36A1) shows nuclear localization and affects growth of smooth muscle cells from rats. Am J Physiol Endocrinol Metab 306:E65-74. https://doi.org/10.1152/ ajpendo.00322.2013

Jing R, Qi T, Wen C, Yue J, Wang G, Pei C, Ma B (2019) Interleukin-2 induces extracellular matrix synthesis and TGF-beta2 expression in retinal pigment epithelial cells. Dev Growth Diff 61:410-418. https://doi.org/10.1111/dgd.12630

Kaarniranta K et al (2006) A mouse model for Stickler's syndrome: ocular phenotype of mice carrying a targeted heterozygous inactivation of type II (pro)collagen gene (Col2a1). Exp Eye Res 83:297-303. https://doi.org/10.1016/j.exer.2005.11.027

Kaiser-Kupfer MI, Caruso RC, Valle D (1991) Gyrate atrophy of the choroid and retina. Long-term reduction of ornithine slows retinal degeneration. Arch Ophthalmol 109:1539-1548

Kanow MA et al (2017) Biochemical adaptations of the retina and retinal pigment epithelium support a metabolic ecosystem in the vertebrate eye. J eLife. https://doi.org/10.7554/eLife.28899

Karna E, Szoka L, Huynh TYL, Palka JA (2020) Proline-dependent regulation of collagen metabolism. Cell Mol Life Sci: CMLS 77:1911-1918. https://doi.org/10.1007/s00018-019-03363-3

Karsdal MA et al (2015) Novel insights into the function and dynamics of extracellular matrix in liver fibrosis. Am J Physiol Gastrointestinal Liver Physiol 308:G807-830. https://doi.org/10.1152/ ajpgi.00447.2014

Kennedy DJ, Gatfield KM, Winpenny JP, Ganapathy V, Thwaites DT (2005) Substrate specificity and functional characterisation of the $\mathrm{H}+/$ amino acid transporter rat PAT2 (Slc36a2). Br J Pharmacol 144:28-41. https://doi.org/10.1038/sj.bjp.0706029

Kermani S et al (1999) Refined genetic and physical positioning of the gene for Doyne honeycomb retinal dystrophy (DHRD). Hum Genet 104:77-82. https://doi.org/10.1007/s004390050913

Kigasawa K, Ishikawa H, Obazawa H, Minamoto T, Nagai Y, Tanaka Y (1998) Collagen production by cultured human retinal pigment epithelial cells. Tokai J Exp Clin Med 23:147-151

Kim JH et al (2014) A genome-wide association study identifies potential susceptibility loci for Hirschsprung disease. PLoS ONE 9:e110292. https://doi.org/10.1371/journal.pone.0110292

Kitchener RL, Grunden AM (2012) Prolidase function in proline metabolism and its medical and biotechnological applications. J Appl Microbiol 113:233-247. https://doi.org/10.1111/j.13652672.2012.05310.x

Kowalczuk S, Broer A, Munzinger M, Tietze N, Klingel K, Broer S (2005) Molecular cloning of the mouse IMINO system: an Na+and $\mathrm{Cl}$-dependent proline transporter. Biochem J 386:417-422. https://doi.org/10.1042/BJ20050100

Kowaloff EM, Phang JM, Granger AS, Downing SJ (1977) Regulation of proline oxidase activity by lactate. Proc Natl Acad Sci USA 74:5368-5371. https://doi.org/10.1073/pnas.74.12.5368

Krishnan N, Dickman MB, Becker DF (2008) Proline modulates the intracellular redox environment and protects mammalian cells against oxidative stress. Free Radical Biol Med 44:671-681. https://doi.org/10.1016/j.freeradbiomed.2007.10.054

Kularatne RN, Bulumulla C, Catchpole T, Takacs A, Christie A, Stefan MC, Csaky KG (2020) Protection of human retinal pigment epithelial cells from oxidative damage using cysteine prodrugs. Free Radical Biol Med 152:386-394. https://doi.org/10.1016/j. freeradbiomed.2020.03.024

Kurihara $\mathrm{T}$ et al (2016) Hypoxia-induced metabolic stress in retinal pigment epithelial cells is sufficient to induce photoreceptor degeneration. Elife. https://doi.org/10.7554/eLife.14319

Lains I et al (2019) Human plasma metabolomics in age-related macular degeneration: meta-analysis of two cohorts. Metabolites. https://doi.org/10.3390/metabo9070127

Lakkaraju A, Umapathy A, Tan LX, Daniele L, Philp NJ, BoeszeBattaglia K, Williams DS (2020) The cell biology of the retinal pigment epithelium. Progress Retinal Eye Res. https://doi.org/ 10.1016/j.preteyeres.2020.100846

Langton KP, McKie N, Curtis A, Goodship JA, Bond PM, Barker MD, Clarke M (2000) A novel tissue inhibitor of metalloproteinases-3 mutation reveals a common molecular phenotype in Sorsby's fundus dystrophy. J Biol Chem 275:27027-27031. https://doi. org/10.1074/jbc.M909677199

Lee JS et al (2016) Association analysis of SLC6A20 polymorphisms with hirschsprung disease. J Pediatric Gastroenterol Nutr 62:6470. https://doi.org/10.1097/MPG.0000000000000880 
Lefevere E, Toft-Kehler AK, Vohra R, Kolko M, Moons L, Van Hove I (2017) Mitochondrial dysfunction underlying outer retinal diseases. Mitochondrion 36:66-76. https://doi.org/10.1016/j. mito.2017.03.006

Li W, Stramm LE, Aguirre GD, Rockey JH (1984) Extracellular matrix production by cat retinal pigment epithelium in vitro: characterization of type IV collagen synthesis. Exp Eye Res 38:291-304. https://doi.org/10.1016/0014-4835(84)90167-2

Li B et al (2020) Metabolic features of mouse and human retinas: rods versus cones, macula versus periphery, retina versus RPE. iScience 23:101672. https://doi.org/10.1016/j.isci.2020.101672

Liang ST et al (2019) Zebrafish carrying pycr1 gene deficiency display aging and multiple behavioral abnormalities. Cells. https://doi.org/10.3390/cells8050453

Liao JL et al (2010) Molecular signature of primary retinal pigment epithelium and stem-cell-derived RPE cells. Hum Mol Genet 19:4229-4238. https://doi.org/10.1093/hmg/ddq341

Liu B et al (2019) Genetic analyses of human fetal retinal pigment epithelium gene expression suggest ocular disease mechanisms. Commun Biol 2:186. https://doi.org/10.1038/ s42003-019-0430-6

Lo AC, Woo TT, Wong RL, Wong D (2011) Apoptosis and other cell death mechanisms after retinal detachment: implications for photoreceptor rescue. Ophthalmol J Int d'ophtalmologie Int J Ophthalmol Zeitschrift fur Augenheilkunde 226(Suppl 1):10-17. https://doi.org/10.1159/000328206

Lodato RF, Smith RJ, Valle D, Phang JM, Aoki TT (1981) Regulation of proline biosynthesis: the inhibition of pyrroline-5-carboxylate synthase activity by ornithine. Metab Clin Exp 30:908-913

Ma Y, Kleinbeck K, Kao WJ (2011) Extracellular matrix-derived tripeptide proline-glycine-proline inhibits keratinocyte proliferation and migration. Wound Repair Regeneration Off Publ Wound Healing Soc Eur Tissue Repair Soc 19:718-726. https://doi.org/ 10.1111/j.1524-475X.2011.00734.x

McDonald AE, Pichaud N, Darveau CA (2018) "Alternative" fuels contributing to mitochondrial electron transport: importance of non-classical pathways in the diversity of animal metabolism. Comparative Biochem Physiol Part B Biochem Mol Biol 224:185-194. https://doi.org/10.1016/j.cbpb.2017.11.006

Meyer J (1977) Proline transport in rat liver mitochondria. Arch Biochem Biophys 178:387-395. https://doi.org/10.1016/00039861(77)90208-9

Misiura M, Miltyk W (2020) Current understanding of the emerging role of prolidase in cellular metabolism. Int J Mol Sci. https:// doi.org/10.3390/ijms21165906

Mitsubuchi H, Nakamura K, Matsumoto S, Endo F (2008) Inborn errors of proline metabolism. J Nutr 138:2016S-2020S. https:// doi.org/10.1093/jn/138.10.2016S

Monboisse JC, Oudart JB, Ramont L, Brassart-Pasco S, Maquart FX (2014) Matrikines from basement membrane collagens: a new anti-cancer strategy. Biochem Biophys Acta 1840:2589-2598. https://doi.org/10.1016/j.bbagen.2013.12.029

Murali A, Krishnakumar S, Subramanian A, Parameswaran S (2020) Bruch's membrane pathology: a mechanistic perspective. Eur J Ophthalmol 30:1195-1206. https://doi.org/10.1177/1120672120 919337

Natarajan SK et al (2012) Proline dehydrogenase is essential for proline protection against hydrogen peroxide-induced cell death. Free Radical Biol Med 53:1181-1191. https://doi.org/10.1016/j.freer adbiomed.2012.07.002

Newman AM et al (2012) Systems-level analysis of age-related macular degeneration reveals global biomarkers and phenotype-specific functional networks. Genome Med 4:16. https://doi.org/10.1186/ gm315

Nikopoulos K et al (2011) Autosomal recessive Stickler syndrome in two families is caused by mutations in the COL9A1 gene.
Investigative Ophthalmol Visual Sci 52:4774-4779. https://doi. org/10.1167/iovs. 10-7128

Nita M, Grzybowski A, Ascaso FJ, Huerva V (2014a) Age-related macular degeneration in the aspect of chronic low-grade inflammation (pathophysiological parainflammation). Mediators inflammation 2014:930671. https://doi.org/10.1155/2014/ 930671

Nita M, Strzalka-Mrozik B, Grzybowski A, Mazurek U, Romaniuk W (2014b) Age-related macular degeneration and changes in the extracellular matrix. Med Sci Monitor: Int Med J Exp Clin Res 20:1003-1016. https://doi.org/10.12659/MSM.889887

Njagi EN, Olembo NK, Pearson DJ (1992) Proline transport by tsetse fly Glossina morsitans flight muscle mitochondria. Comparative Biochem Physiol B Comparative Biochem 102:579-584. https://doi.org/10.1016/0305-0491(92)90050-2

Nogusa Y, Mizugaki A, Hirabayashi-Osada Y, Furuta C, Ohyama K, Suzuki K, Kobayashi H (2014) Combined supplementation of carbohydrate, alanine, and proline is effective in maintaining blood glucose and increasing endurance performance during long-term exercise in mice. J Nutr Sci Vitaminol 60:188-193. https://doi.org/10.3177/jnsv.60.188

O'Donnell JJ, Sandman RP, Martin SR (1978) Gyrate atrophy of the retina: inborn error of L-ornithin:2-oxoacid aminotransferase. Science 200:200-201

Ogata A, Tanaka S, Tomoda T, Murayama E, Endo F, Kikuchi I (1981) Autosomal recessive prolidase deficiency. Three patients with recalcitrant ulcers. Arch Dermatol 117:689-697

Olivares $\mathrm{O}$ et al (2017) Collagen-derived proline promotes pancreatic ductal adenocarcinoma cell survival under nutrient limited conditions. Nat Commun 8:16031. https://doi.org/10.1038/ ncomms 16031

Pandhare J, Donald SP, Cooper SK, Phang JM (2009) Regulation and function of proline oxidase under nutrient stress. J Cell Biochem 107:759-768. https://doi.org/10.1002/jcb.22174

Patel DF, Snelgrove RJ (2018) The multifaceted roles of the matrikine Pro-Gly-Pro in pulmonary health and disease. Eur Respiratory Rev Off J Eur Respiratory Soc. https://doi.org/10. 1183/16000617.0017-2018

Phang JM, Liu W, Zabirnyk O (2010) Proline metabolism and microenvironmental stress. Ann Rev Nutr 30:441-463. https://doi. org/10.1146/annurev.nutr.012809.104638

Pillai SM, Meredith D (2011) SLC36A4 (hPAT4) is a high affinity amino acid transporter when expressed in Xenopus laevis oocytes. J Biol Chem 286:2455-2460. https://doi.org/10.1074/ jbc.M110.172403

Pinilla-Tenas J, Barber A, Lostao MP (2003) Transport of proline and hydroxyproline by the neutral amino-acid exchanger ASCT1. J Membrane Biol 195:27-32. https://doi.org/10.1007/ s00232-003-2041-9

Radeke MJ, Radeke CM, Shih YH, Hu J, Bok D, Johnson LV, Coffey PJ (2015) Restoration of mesenchymal retinal pigmented epithelial cells by TGFbeta pathway inhibitors: implications for age-related macular degeneration. Genome Med 7:58. https:// doi.org/10.1186/s 13073-015-0183-x

Radtke ND, Weinsieder AD, Ballou RJ (1986) Pharmacological therapy for proliferative vitreoretinopathy Graefe's archive for clinical and experimental ophthalmology = Albrecht von Graefes Archiv fur klinische und experimentelle. Ophthalmologie 224:230-233. https://doi.org/10.1007/BF02143060

Ratnapriya R et al (2019) Retinal transcriptome and eQTL analyses identify genes associated with age-related macular degeneration. Nat Genet 51:606-610. https://doi.org/10.1038/ s41588-019-0351-9

Reyes-Reveles J, Dhingra A, Alexander D, Bragin A, Philp NJ, Boesze-Battaglia K (2017) Phagocytosis-dependent 
ketogenesis in retinal pigment epithelium. J Biol Chem 292:8038-8047. https://doi.org/10.1074/jbc.M116.770784

Ricard-Blum S (2011) The collagen family. Cold Spring Harbor Perspectives Biol 3:a004978. https://doi.org/10.1101/cshpe rspect.a004978

Richards AJ, Yates JR, Williams R, Payne SJ, Pope FM, Scott JD, Snead MP (1996) A family with Stickler syndrome type 2 has a mutation in the COL11A1 gene resulting in the substitution of glycine 97 by valine in alpha 1 (XI) collagen. Human Mol Genet 5:1339-1343. https://doi.org/10.1093/hmg/5.9.1339

Richards AJ et al (2000) Variation in the vitreous phenotype of Stickler syndrome can be caused by different amino acid substitutions in the X position of the type II collagen Gly-X-Y triple helix. Am J Hum Genet 67:1083-1094. https://doi.org/ 10.1016/S0002-9297(07)62938-3

Rosales MAB, Shu DY, Iacovelli J, Saint-Geniez M (2019) Loss of PGC-1alpha in RPE induces mesenchymal transition and promotes retinal degeneration. Life Sci Alliance. https://doi. org/10.26508/lsa.201800212

Saito T, Hayasaka S, Yabata K, Omura K, Mizuno K, Tada K (1981) Atypical gyrate atrophy of the choroid and retina and iminoglycinuria. Tohoku J Exp Med 135:331-332

Schroder B et al (2007) Integral and associated lysosomal membrane proteins. Traffic 8:1676-1686. https://doi.org/10.1111/j.16000854.2007.00643.x

Senanayake P, Calabro A, Hu JG, Bonilha VL, Darr A, Bok D, Hollyfield JG (2006) Glucose utilization by the retinal pigment epithelium: evidence for rapid uptake and storage in glycogen, followed by glycogen utilization. Exp Eye Res 83:235-246. https://doi.org/10.1016/j.exer.2005.10.034

Seo C, Hwang YH, Kim Y, Joo BS, Yee ST, Kim CM, Paik MJ (2016) Metabolomic study of aging in mouse plasma by gas chromatography-mass spectrometry. J Chromatogr B Anal Technol Biomed Life Sci 1025:1-6. https://doi.org/10.1016/j. jchromb.2016.04.052

Shafqat S, Velaz-Faircloth M, Henzi VA, Whitney KD, Yang-Feng TL, Seldin MF, Fremeau RT Jr (1995) Human brain-specific L-proline transporter: molecular cloning, functional expression, and chromosomal localization of the gene in human and mouse genomes. Mol Pharmacol 48:219-229

Shu X et al (2011) Characterisation of a C1qtnf5 Ser163Arg knock-in mouse model of late-onset retinal macular degeneration. PLoS ONE 6:e27433. https://doi.org/10.1371/journal.pone.0027433

Singer D et al (2012) Defective intestinal amino acid absorption in Ace2 null mice. Am J Physiol Gastrointestinal Liver Physiol 303:G686-695. https://doi.org/10.1152/ajpgi.00140.2012

Smith PR, Bain SC, Good PA, Hattersley AT, Barnett AH, Gibson JM, Dodson PM (1999) Pigmentary retinal dystrophy and the syndrome of maternally inherited diabetes and deafness caused by the mitochondrial DNA 3243 tRNA(Leu) A to G mutation. Ophthalmology 106:1101-1108. https://doi.org/10.1016/ S0161-6420(99)90244-0

Stone EM et al (1999) A single EFEMP1 mutation associated with both Malattia Leventinese and Doyne honeycomb retinal dystrophy. Nat Genet 22:199-202. https://doi.org/10.1038/9722

Strunnikova NV et al (2010) Transcriptome analysis and molecular signature of human retinal pigment epithelium. Hum Mol Genet 19:2468-2486. https://doi.org/10.1093/hmg/ddq129

Swarup A et al (2019) Modulating GLUT1 expression in retinal pigment epithelium decreases glucose levels in the retina: impact on photoreceptors and Muller glial cells. Am J Physiol Cell Physiol 316:C121-C133. https://doi.org/10.1152/ajpcell. 00410.2018

Takanaga H, Mackenzie B, Peng JB, Hediger MA (2005a) Characterization of a branched-chain amino-acid transporter SBAT1 (SLC6A15) that is expressed in human brain. Biochem Biophys
Res Commun 337:892-900. https://doi.org/10.1016/j.bbrc.2005. 09.128

Takanaga H, Mackenzie B, Suzuki Y, Hediger MA (2005b) Identification of mammalian proline transporter SIT1 (SLC6A20) with characteristics of classical system imino. J Biol Chem 280:89748984. https://doi.org/10.1074/jbc.M413027200

Tan EM, Ryhanen L, Uitto J (1983) Proline analogues inhibit human skin fibroblast growth and collagen production in culture. J Invest Dermatol 80:261-267. https://doi.org/10.1111/1523-1747.ep125 34593

Tan W, Zou J, Yoshida S, Jiang B, Zhou Y (2020) The role of inflammation in age-related macular degeneration. Int J Biol Sci 16:2989-3001. https://doi.org/10.7150/ijbs.49890

Tarttelin EE, Gregory-Evans CY, Bird AC, Weleber RG, Klein ML, Blackburn J, Gregory-Evans K (2001) Molecular genetic heterogeneity in autosomal dominant drusen. J Med Genet 38:381-384. https://doi.org/10.1136/jmg.38.6.381

Terluk MR et al (2019) N-Acetyl-L-cysteine protects human retinal pigment epithelial cells from oxidative damage: implications for age-related macular degeneration. Oxidative Med Cell Longevity 2019:5174957. https://doi.org/10.1155/2019/5174957

Tian B et al (2015) Analysis of the TGFbeta-induced program in primary airway epithelial cells shows essential role of NF-kappaB/ RelA signaling network in type II epithelial mesenchymal transition. BMC Genomics 16:529. https://doi.org/10.1186/ s12864-015-1707-X

Ueda M, Masu Y, Ando A, Maeda H, Del Monte MA, Uyama M, Ito S (1998) Prevention of ornithine cytotoxicity by proline in human retinal pigment epithelial cells. Investigative Ophthalmol Visual Sci 39:820-827

Uitto J, Ryhanen L, Tan EM, Oikarinen AI, Zaragoza EJ (1984) Pharmacological inhibition of excessive collagen deposition in fibrotic diseases. Fed Proc 43:2815-2820

Van Camp G et al (2006) A new autosomal recessive form of Stickler syndrome is caused by a mutation in the COL9A1 gene. Am J Human Genet 79:449-457. https://doi.org/10.1086/506478

van de Water TR, Galinovic-Schwartz V (1986) Dysmorphogenesis of the inner ear: disruption of extracellular matrix (ECM) formation by an L-proline analog in otic explants. J Craniofacial Genet Dev Biol 6:113-129

Wang T, Lawler AM, Steel G, Sipila I, Milam AH, Valle D (1995) Mice lacking ornithine-delta-aminotransferase have paradoxical neonatal hypoornithinaemia and retinal degeneration. Nat Genet 11:185-190. https://doi.org/10.1038/ng1095-185

Wang T, Steel G, Milam AH, Valle D (2000) Correction of ornithine accumulation prevents retinal degeneration in a mouse model of gyrate atrophy of the choroid and retina. Proc Natl Acad Sci USA 97:1224-1229

Wang Y et al (2018) Metabolic signature of the aging eye in mice. Neurobiol Aging 71:223-233. https://doi.org/10.1016/j.neuro biolaging.2018.07.024

Wang A et al (2020) Single-cell multiomic profiling of human lungs reveals cell-type-specific and age-dynamic control of SARSCoV2 host genes. Elife. https://doi.org/10.7554/eLife.62522

Waumans Y, Baerts L, Kehoe K, Lambeir AM, De Meester I (2015) The dipeptidyl peptidase family, prolyl oligopeptidase, and prolyl carboxypeptidase in the immune system and inflammatory disease, including atherosclerosis. Front Immunol 6:387. https:// doi.org/10.3389/fimmu.2015.00387

Weber BH, Vogt G, Pruett RC, Stohr H, Felbor U (1994) Mutations in the tissue inhibitor of metalloproteinases-3 (TIMP3) in patients with Sorsby's fundus dystrophy. Nat Genet 8:352-356. https:// doi.org/10.1038/ng1294-352

Weber BH et al (2002) A mouse model for Sorsby fundus dystrophy. Investigative Ophthalmol Visual Sci 43:2732-2740 
Wolthuis DF, van Asbeck E, Mohamed M, Gardeitchik T, Lim-Melia ER, Wevers RA, Morava E (2014) Cutis laxa, fat pads and retinopathy due to ALDH18A1 mutation and review of the literature. Eur J Paediatric Neurol EJPN Off J Eur Paediatric Neurol Soc 18:511-515. https://doi.org/10.1016/j.ejpn.2014.01.003

Wu G, Fang YZ, Yang S, Lupton JR, Turner ND (2004) Glutathione metabolism and its implications for health. J Nutr 134:489-492. https://doi.org/10.1093/jn/134.3.489

Wu G, Bazer FW, Hu J, Johnson GA, Spencer TE (2005) Polyamine synthesis from proline in the developing porcine placenta. Biol Reprod 72:842-850. https://doi.org/10.1095/biolreprod.104. 036293

Wu G et al (2011) Proline and hydroxyproline metabolism: implications for animal and human nutrition. Amino Acids 40:10531063. https://doi.org/10.1007/s00726-010-0715-z

Xie X et al (2019) Associations of SLC6A20 genetic polymorphisms with Hirschsprung's disease in a Southern Chinese population. Biosci Rep. https://doi.org/10.1042/BSR20182290

$\mathrm{Xu} \mathrm{R}$ et al (2020) The retina and retinal pigment epithelium differ in nitrogen metabolism and are metabolically connected. J Biol Chem. https://doi.org/10.1074/jbc.RA119.011727

Yam M et al (2019) Proline mediates metabolic communication between retinal pigment epithelial cells and the retina. J Biol Chem 294:10278-10289. https://doi.org/10.1074/jbc.RA119. 007983

Yasukawa T, Kimura H, Tabata Y, Miyamoto H, Honda Y, Ogura Y (2002) Sustained release of cis-hydroxyproline in the treatment of experimental proliferative vitreoretinopathy in rabbits Graefe's archive for clinical and experimental ophthalmology $=$ Albrecht von Graefes Archiv fur klinische und experimentelle. Ophthalmologie 240:672-678. https://doi.org/10.1007/ s00417-002-0484-9

Yoo JS et al (1997) cis-Hydroxyproline inhibits proliferation, collagen synthesis, attachment, and migration of cultured bovine retinal pigment epithelial cells. Investigative Ophthalmol Visual Sci 38:520-528

Zaia KA, Reimer RJ (2009) Synaptic vesicle protein NTT4/XT1 (SLC6A17) catalyzes Na+-coupled neutral amino acid transport. J Biol Chem 284:8439-8448. https://doi.org/10.1074/jbc. M806407200

Zhang $\mathrm{R}$ et al (2021) Inhibition of mitochondrial respiration impairs nutrient consumption and metabolite transport in human retinal pigment epithelium. J Proteome Res 20:909-922. https://doi.org/ 10.1021/acs.jproteome.0c00690

Zhao C et al (2011a) mTOR-mediated dedifferentiation of the retinal pigment epithelium initiates photoreceptor degeneration in mice. J Clin Investigation 121:369-383. https://doi.org/10.1172/JCI44 303

Zhao Z, Chen Y, Wang J, Sternberg P, Freeman ML, Grossniklaus HE, Cai J (2011b) Age-related retinopathy in NRF2-deficient mice. PLoS ONE 6:e19456. https://doi.org/10.1371/journal.pone. 0019456

Zheng X et al (2016) Metabolic reprogramming during neuronal differentiation from aerobic glycolysis to neuronal oxidative phosphorylation. Elife. https://doi.org/10.7554/eLife.13374

Zhou M, Geathers JS, Grillo SL, Weber SR, Wang W, Zhao Y, Sundstrom JM (2020) Role of epithelial-mesenchymal transition in retinal pigment epithelium dysfunction. Front Cell Dev Biol 8:501. https://doi.org/10.3389/fcell.2020.00501

Publisher's Note Springer Nature remains neutral with regard to jurisdictional claims in published maps and institutional affiliations. 